University of Nebraska - Lincoln

DigitalCommons@University of Nebraska - Lincoln

USGS Staff -- Published Research

US Geological Survey

2012

\title{
Agricultural Drought Monitoring in Kenya Using Evapotranspiration Derived from Remote Sensing and Reanalysis Data
}

\author{
Michael T. Marshall \\ University of California, Santa Barbara \\ Christopher Funk \\ U.S. Geological Survey, chris@geog.ucsb.edu \\ Joel Michaelsen \\ University of California, Santa Barbara, joel@geog.ucsb.edu
}

Follow this and additional works at: http://digitalcommons.unl.edu/usgsstaffpub

Part of the Geology Commons, Oceanography and Atmospheric Sciences and Meteorology Commons, Other Earth Sciences Commons, and the Other Environmental Sciences Commons

Marshall, Michael T.; Funk, Christopher; and Michaelsen, Joel, "Agricultural Drought Monitoring in Kenya Using Evapotranspiration Derived from Remote Sensing and Reanalysis Data" (2012). USGS Staff -- Published Research. 978.

http:// digitalcommons.unl.edu/usgsstaffpub/978

This Article is brought to you for free and open access by the US Geological Survey at DigitalCommons@University of Nebraska - Lincoln. It has been accepted for inclusion in USGS Staff -- Published Research by an authorized administrator of DigitalCommons@University of Nebraska - Lincoln. 
Published in Remote Sensing of Drought: Innovative Monitoring Approaches, edited by Brian D. Wardlow, Martha C. Anderson, \& James P. Verdin (CRC Press/Taylor \& Francis, 2012).

This chapter is a U.S. government work and is not subject to copyright in the United States.

Authors:

\section{Michael T. Marshall}

Department of Geography

University of California, Santa Barbara

Santa Barbara, California

\section{Christopher Funk}

Earth Resources Observation and Science Center

U.S. Geological Survey

Sioux Falls, South Dakota

\section{Joel Michaelsen}

Department of Geography

University of California, Santa Barbara

Santa Barbara, California 


\title{
8 Agricultural Drought Monitoring in Kenya Using Evapotranspiration Derived from Remote Sensing and Reanalysis Data
}

\author{
Michael T. Marshall, Christopher Funk, \\ and Joel Michaelsen
}

\section{CONTENTS}

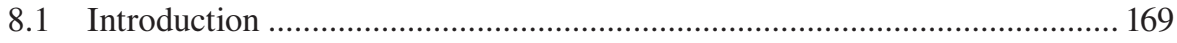

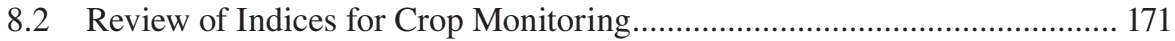

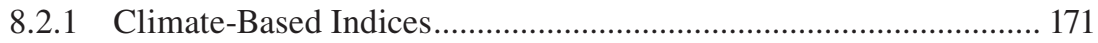

8.2.2 Satellite-Based Indices ................................................................ 172

8.3 Description of the Evapotranspiration Model .............................................. 173

8.3.1 Theoretical Background ............................................................... 173

8.3.2 Data Handling and Processing …………………........................... 176

8.4 Model Calibration and Validation ................................................................ 176

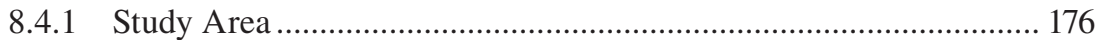

8.4.2 Evapotranspiration and Crop Yield ................................................ 178

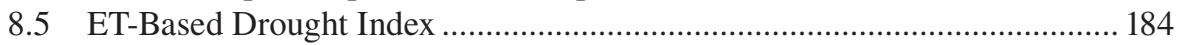

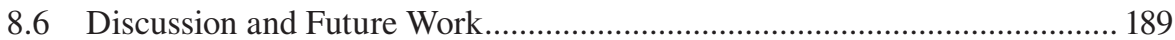

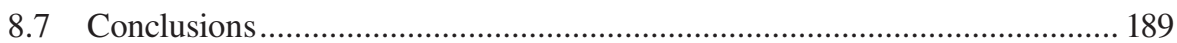

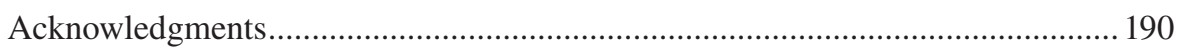

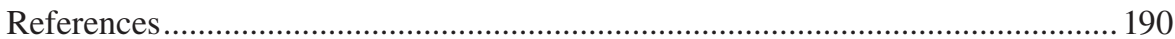

\subsection{INTRODUCTION}

More than half of the people in sub-Saharan Africa live on less than US $\$ 1.25$ per day, and nearly $30 \%$ do not receive sufficient nourishment to maintain daily health (UN, 2009a). These figures are expected to rise as a result of the recent global financial crisis that has led to an increase in food prices. Food for Peace (FFP), the program 
that administers more than $85 \%$ of U.S. international food aid, recently reported that the seven largest recipient countries of food aid worldwide are in sub-Saharan Africa (FFP, 2010). In Kenya, the fifth largest recipient of food aid from FFP and a country highly dependent on rainfed agriculture, below-average precipitation in 2009 led to a $20 \%$ reduction in maize production and a $100 \%$ increase in domestic maize prices (FEWS NET, 2009). Given these sorts of climatic shocks, it is imperative that mitigation strategies be developed for sub-Saharan Africa and other regions of the developing world to improve the international and national response to impending food crises. Crop monitoring is an important tool used by national agricultural offices and other stakeholders to inform food security analyses and agricultural drought mitigation. Remote sensing and surface reanalysis data facilitate efficient and cost-effective approaches to measuring determinants of agricultural drought. In this chapter, we explore how remotely sensed estimates of actual evapotranspiration $\left(\mathrm{ET}_{\mathrm{a}}\right)$ can be integrated with surface reanalysis data to augment agricultural drought monitoring systems.

Although water availability is important throughout every stage of crop development, from germination to harvest, crops are most sensitive to moisture deficits during the reproductive stages (Shanahan and Nielsen, 1987). A study that analyzed maize, for example, showed that a $1 \%$ decline in seasonal $\mathrm{ET}_{\mathrm{a}}$ led to an average loss of $1.5 \%$ in crop yield, whereas water stress in the same proportion concentrated during the reproductive phases led to a $2.6 \%$ decline in crop yield (Stegman, 1982). Agricultural drought can therefore be defined as inadequate soil water availability, particularly during the reproductive phase, caused by low precipitation, insufficient water-holding capacity in the root zone of the soil, and/or high atmospheric water demand (potential evapotranspiration, $\mathrm{ET}_{\mathrm{p}}$ ), which results in a reduction in crop yield. Agricultural droughts differ in timescale and impact from shorter-term meteorological droughts, which are characterized by negative precipitation anomalies on the order of days to weeks, and the longer-term negative runoff and water storage anomalies that characterize hydrological drought (Dracup et al., 1980).

Deficits in $\mathrm{ET}_{\mathrm{a}}$ are a direct measure of crop stress and can be integrated into agricultural drought monitoring systems. In response to large soil moisture deficits, for example, plants close their stomata, thereby downregulating water and $\mathrm{CO}_{2}$ exchange with the atmosphere (Jones, 1992). This protects plants from excessive water loss and cavitation and reduces $\mathrm{ET}_{\mathrm{a}}$, which is the quantity of moisture that is lost to the atmosphere via wet canopy and soil evaporation and transpiration. There are several options for integrating $\mathrm{ET}_{\mathrm{a}}$ estimates into agricultural drought monitoring. One possibility is using $\mathrm{ET}_{\mathrm{a}}$ anomalies derived from a suite of observed, reanalysis, and remote sensing data to provide a simple means for assessing crop stress, although this approach would have limited use in the most agriculturally intensive regions of the developing world where the variability in soil moisture (and therefore variability in $\mathrm{ET}_{\mathrm{a}}$ ) is low. A more sophisticated application would involve a crop model that uses $\mathrm{ET}_{\mathrm{a}}$ explicitly to determine impact of moisture anomalies on start of season, length of growing period, crop yield, and water availability. The major disadvantage of this approach in data-sparse regions is that the models require detailed meteorological data derived from a dense network of weather stations. Remote sensing and 
surface reanalysis meteorological models, however, have made this approach more feasible in recent decades.

In this chapter, an $\mathrm{ET}_{\mathrm{a}}$-based crop index that represents a balance between simple and complex monitoring tools is presented and applied in sub-Saharan Africa to illustrate its utility in monitoring agricultural drought. Given the scarcity of observational data in the region, an $\mathrm{ET}_{\mathrm{a}}$ model is used to derive the index. The model is a hybrid that combines components of two models that were parameterized with freely available remote sensing and surface reanalysis meteorological data. The $\mathrm{ET}_{\mathrm{a}}$ model was evaluated for major biomes throughout sub-Saharan Africa using eddy covariance flux tower data in Marshall et al. (2011). This chapter builds on the previous work by extending model performance using district-level crop yield data. An ET a $^{-}$ based crop index derived from the model is then applied to food security analysis. The index is compared qualitatively against the Standardized Precipitation Index (SPI), which is a common index used to monitor agricultural droughts in this region of Africa. The chapter concludes with recommendations on how to integrate the $\mathrm{ET}_{\mathrm{a}}$ based index into a regular monitoring scheme and a brief, general discussion regarding the future direction of agricultural drought monitoring in sub-Saharan Africa.

\subsection{REVIEW OF INDICES FOR CROP MONITORING}

\subsubsection{Climate-Based Indices}

McGuire and Palmer (1957) were the first to develop an index specifically for agricultural drought monitoring. The index was simply the ratio of atmospheric water demand $\left(\mathrm{ET}_{\mathrm{p}}\right)$ to supply (precipitation + soil moisture). The resulting Moisture Adequacy Index (MAI) is a relative measure of the moisture available to support normal plant functions. Crops are assumed to be under stress when water demand is much greater than supply. Since the development of the MAI, several other conceptually simple indices have been developed that are better able to capture the spatiotemporal complexities of an agricultural drought. Heim (2002) provides a thorough review of agricultural drought indices commonly used in the United States and globally.

The most notable achievement in crop monitoring occurred shortly after the development of MAI with the application of a simple water balance model to evaluate meteorological droughts (Palmer, 1965). The Palmer Drought Severity Index (PDSI) measures the precipitation required to balance the changes in moisture inputs (precipitation and soil recharge) with outputs (ET $\mathrm{a}$ and runoff). A two-layer soil profile is used to estimate runoff and soil moisture recharge from the difference between precipitation and $\mathrm{ET}_{\mathrm{a}}$, which is calculated as the excess $\mathrm{ET}_{\mathrm{p}}$ above precipitation. PDSI is typically standardized using a climatologically driven weighting function to yield the Moisture Anomaly Index (PDSI-z). PDSI-z responds to moisture conditions over short periods of time, so it is more appropriately used for identifying meteorological and agricultural droughts (Karl, 1986). In addition, PDSI-z is a standardized index, making its application across regions more appropriate than PDSI for meteorological and agricultural droughts. Palmer (1965) also developed the Crop Moisture Index (CMI), which uses PDSI constrained by dry and wet ranges to identify agricultural droughts. There is 
overlap between the dry and wet ranges, often leading to contradictions in drought onset and cessation. Alley (1984) gives a thorough description of PDSI and CMI, including sources of error and major limitations when applied to agricultural drought.

The strong dependence of PDSI on rainfall has contributed to the development of precipitation-based indices, the most notable of which is the SPI (McKee et al., 1993). Although the SPI has been used primarily to monitor meteorological droughts, it is scalable and has been applied successfully to agricultural drought monitoring as well (Keyantash and Dracup, 2002). The index is a standardized representation of the deviation of rainfall probabilities from the long-term mean. These probabilities are typically approximated using a gamma or Pearson III distribution (Guttman, 1999). In contrast with the PDSI-z, the SPI requires fewer potentially uncertain inputs, it can be estimated at various temporal scales, and its physical meaning is easier to interpret.

\subsubsection{Satellite-Based Indices}

Satellite observations of vegetation conditions have provided another basis for crop monitoring. The Normalized Difference Vegetation Index (NDVI) (Rouse et al., 1974), derived from remotely sensed visible and near-infrared reflectance, is sensitive to the photosynthetic capacity of plants and typically lags precipitation by $1-2$ months in sub-Saharan Africa (Nicholson et al., 1990). NDVI has been used to characterize trends in vegetation (Philippon et al., 2007) and interannual variability in precipitation (Anyamba and Eastman, 1996). A common approach to monitoring crop stress using NDVI is to combine it with remotely sensed temperature, yielding a composite index such as the Vegetation Health Index (VHI) (Kogan, 1995). The inclusion of temperature conveys additional information on drought conditions (e.g., soil dryness, plant stress) not captured by NDVI alone. VHI assumes that NDVI and surface temperature are inversely related and is therefore useful where soil moisture is a constraint on plant health. In canopies found commonly in tropical Africa, plants are light limited. In these cases, temperature and NDVI are directly related, because plants prefer to photosynthesize at warmer temperatures when moisture is not a limiting factor (Karnieli et al., 2006). The uncertainty in the NDVI-temperature relationship for different climatic zones and land cover types therefore makes regional drought monitoring difficult with VHI.

Most recently, process-based models of $\mathrm{ET}_{\mathrm{a}}$ have been used to develop indices for agricultural drought monitoring. Unlike precipitation, $\mathrm{ET}_{\mathrm{a}}$ takes into account additional factors contributing to crop stress, including vegetation type and phenology, antecedent soil moisture conditions, and soil properties (Narasimhan and Srinivasan, 2005). In addition, $\mathrm{ET}_{\mathrm{a}}$-based indices are more sensitive than precipitation-based indices to gradual changes in soil moisture and crop stress that occur during agricultural droughts. An $\mathrm{ET}_{\mathrm{a}}$-based index used extensively in sub-Saharan Africa is the Water Requirement Satisfaction Index (WRSI), first developed by the United Nations (UN) Food and Agriculture Organization (FAO) (Doorenbos and Pruitt, 1977). WRSI is the ratio of $\mathrm{ET}_{\mathrm{a}}$ to $\mathrm{ET}_{0}$, the reference evapotranspiration adjusted by an empirically derived coefficient that accounts for crop type and its specific growth stage. $\mathrm{ET}_{0}$ is derived for a wet grass using the Monteith (1965) equation driven by surface net radiation, temperature, and vapor pressure. WRSI uses a 
simple bucket model, with no soil profile, making $\mathrm{ET}_{\mathrm{a}}$ essentially a residual of $\mathrm{ET}_{\mathrm{p}}$ and precipitation (Senay and Verdin, 2003). Given the complexities of modeling $\mathrm{ET}_{\mathrm{a}}$ in data-sparse regions, the major disadvantages of the model are that start season and length of growing period are estimated from NDVI, the required climate data tend to have very coarse spatial resolution, and $\mathrm{ET}_{\mathrm{p}}$ is derived from an empirical relationship between the crop coefficient and $\mathrm{ET}_{0}$. In reality, this coefficient varies dramatically across land cover types, as well as intra- and interseasonally, making its application over broad areas and time frames difficult (Allen, 2000). Anderson et al. (2007) developed the Evaporative Stress Index (ESI) for the United States, which is conceptually similar to WRSI, but uses an energy balance approach to estimate $\mathrm{ET}_{\mathrm{a}}$. Unlike bucket models, the energy balance approach avoids assumptions of the soil profile and requires vegetation and temperature inputs, which are more certain than remotely sensed precipitation data in sub-Saharan Africa. The approach, however, does require land-surface temperature (LST) derived from thermal satellite data acquired under clear-sky conditions, which is limited by periods of persistent lowlevel stratus cloud cover that tends to obscure conditions during the dry season in the most food insecure (subtropical) region of Africa.

\subsection{DESCRIPTION OF THE EVAPOTRANSPIRATION MODEL}

\subsubsection{Theoretical Background}

The use of temporally continuous surface reanalysis meteorological data can enhance temporally coarse resolution remote sensing data used to develop $\mathrm{ET}_{\mathrm{a}}$-driven indices for crop monitoring applications where dense climate data networks are unavailable. Surface reanalysis meteorological data are developed from the synthesis of remote sensing, global circulation models (GCMs), and meteorological station data using a suite of sophisticated assimilation techniques. Recently, Marshall et al. (2010) evaluated two fundamentally different approaches to estimating $\mathrm{ET}_{\mathrm{a}}$, both driven by the Global Land Data Assimilation System (GLDAS) surface reanalysis data set (Rodell et al., 2004). One approach was driven primarily by remotely sensed vegetation, and the other approach was driven primarily by surface reanalysis precipitation. The former is described in detail in Fisher et al. (2008) and will be identified as the Fisher model for this chapter. The Fisher model uses a series of vegetation and soil moisture factors to constrain $\mathrm{ET}_{\mathrm{p}}$. The constraints are intentionally simplified to facilitate easy application over large data-poor areas. The second approach, called the National Centers for Environmental Prediction, Oregon State University, Air Force, and Hydrologic Research Lab (Noah) Land Surface Model, is described in detail in Chen et al. (2007). Both approaches compute $\mathrm{ET}_{\mathrm{a}}$ as the sum of transpiration $\left(E T_{c}\right)$, wet canopy evaporation $\left(\mathrm{ET}_{\mathrm{i}}\right)$, and bare soil evaporation (ET). Marshall et al. (2010) demonstrated that $E T_{c}$ from the Fisher model, which included a dynamic vegetation component, performed particularly well with reanalysis data for energy-limited (humid) sites, while Noah more accurately captured the soil and wet canopy components in moisture-limited (dry) sites. This led to the integration of $E T_{c}$ of the Fisher model with $\mathrm{ET}_{\mathrm{s}}$ and $\mathrm{ET}_{\mathrm{i}}$ from the Noah model to provide a more robust ET estimation over a range of environmental conditions. The components of the model are described in detail later. 
In the hybrid $\mathrm{ET}_{\mathrm{a}}$ formulation, the transpiration component of the Fisher model uses the Priestley and Taylor (1972) equilibrium equation for $\mathrm{ET}_{\mathrm{p}}$ and retains the Priestley-Taylor advection coefficient $(\alpha=1.26) . E T_{c}$ is estimated by constraining Priestley-Taylor ET $_{\mathrm{p}}$ (the term in square brackets in Equation 8.1) by five coefficients analogous to the Jarvis and McNaughton (1986) decoupling coefficient $(\Omega)$ :

$$
E T_{c}=f_{c} f_{g} f_{t} f_{m}\left(1-f_{w e t}\right)\left[\frac{\alpha \Delta}{\Delta+\gamma} R_{N}\right]
$$

where $f_{c}, f_{g}, f_{t}, f_{m}$, and $f_{\text {wet }}$ are total vegetation fraction, photosynthetically active canopy fraction, air temperature constraint, plant moisture constraint, and relative surface wetness, respectively. The constraints for $E T_{c}$ are defined for daylight hours only, when the contribution of ET to the atmospheric water balance is significantly larger than at nighttime. At dekadal or monthly time steps, which are generally used for agricultural drought monitoring in sub-Saharan Africa, soil heat flux is negligible and therefore has been omitted from the equation. $\mathrm{ET}_{\mathrm{p}}$ is defined by three terms: slope of the saturation-to-vapor pressure curve $(\Delta)$, psychometric constant $(\gamma)$, and daytime net radiation $\left(R_{N}\right)$ in mass units. The vegetation cover fraction $f_{c}$ is used to constrain $R_{N}$ in terms of the canopy portion of $\mathrm{ET}_{\mathrm{a}}$ and is calculated as a linear function of NDVI. Early studies showed that NDVI is highly correlated with $f_{c}$ calculated from Beer's law (Sellers, 1987). The active green vegetation cover fraction $\left(f_{g}\right)$ is computed as the ratio of $\mathrm{f}_{\mathrm{APAR}}$ to $f_{c}$, where $\mathrm{f}_{\mathrm{APAR}}$ is the fraction of absorbed photosynthetically active radiation, estimated using a linear function of the Enhanced Vegetation Index (EVI) (Huete et al., 2002). Two different vegetation indices were used in these calculations, because EVI is sensitive to the chlorophyll content (photosynthetically active portion) of the canopy, while NDVI is more effective in capturing the total biomass of the canopy (Huete et al., 2002). The temperature constraint $f_{t}$ assumes that photosynthesis will increase with air temperature until an optimal temperature is achieved (June et al., 2004), and once the temperature becomes higher than the optimal temperature, there is a decline in photosynthesis at a proportional rate. Optimal temperature is defined as the temperature at which the ratio of $\mathrm{f}_{\mathrm{APAR}}$ and available radiation to the vapor pressure deficit (VPD) is maximum. It ranges from near $0^{\circ} \mathrm{C}$ in the $\operatorname{Arctic}$ to $35^{\circ} \mathrm{C}$ in subtropical deserts (Potter et al., 1993). The plant moisture constraint $f_{m}$ is defined as the relative change in light absorptance $\left(\mathrm{f}_{\mathrm{APAR}} /\right.$ maximum $\left.\mathrm{f}_{\mathrm{APAR}}\right)$, assuming that plant moisture stress (moisture availability) varies with the amount of light a plant absorbs. When a plant is moisture stressed, it will close its stomata (reduce photosynthesis) to prevent cavitation. Maximum $\mathrm{f}_{\mathrm{APAR}}$ is determined over the available time series using the equation for $\mathrm{f}_{\mathrm{APAR}}$ (function of EVI) defined earlier. The factor $f_{\text {wet }}$ gives the probability that the surface is wet, defined as a function of near-surface relative humidity. The constraint assumes that during daylight hours, when relative humidity is at $100 \%$, the surface is completely wetted and will evaporate moisture from the wet canopy and bare soil portions to meet atmospheric demand. In this case, $E T_{c}$ approaches 0 . On the other hand, when relative humidity approaches $0 \%$, the surface is completely dry, and the contribution from the wet canopy and soil components to $\mathrm{ET}_{\mathrm{a}}$ is 0 . This constraint is an integral component 
of the wet canopy and soil evaporation components of the Fisher model (not shown here), which the Marshall et al. (2010) study revealed was particularly sensitive to specific humidity, a highly uncertain surface reanalysis variable (Kalnay et al., 1996). The model parameterization further amplified these errors.

The Noah model, first described by Chen et al. (1996), takes a water balance approach to estimating $\mathrm{ET}_{\mathrm{a}}$. The soil evaporation component of the model was based on the work of Mahfouf and Noilhan (1991), who compared several approaches to estimating soil evaporation and found that the preferred method constrains $\mathrm{ET}_{\mathrm{p}}$, as defined in Penman (1948), by a moisture availability parameter $(\beta)$. This parameter is driven by soil moisture using the following equation:

$$
\beta=\left(\frac{\Theta_{1}-\Theta_{w}}{\Theta_{r e f}-\Theta_{w}}\right)^{f}
$$

where

$\Theta_{1}$ is the soil moisture in the top soil layer

$\Theta_{w}$ is the wilting point

$\Theta_{r e f}$ is the field capacity of the soil

$f$ is a constant (Betts et al., 1997)

The wet canopy component of the Noah model, which tends to represent the smallest contribution to total $\mathrm{ET}_{\mathrm{a}}$, is computed as $\mathrm{ET}_{\mathrm{p}}$ constrained by the amount of precipitation intercepted by the canopy (ratio of intercepted canopy water content to maximum canopy water capacity). The transpiration component of the Noah model (not shown here) is driven primarily by the total vegetation fraction, which is derived from NDVI climatological means (Hogue et al., 2005). This tends to make the model insensitive to large phenological changes that are typical in semiarid regions found throughout most of sub-Saharan Africa.

The hybrid model uses $E T_{c}$ from the Fisher model and $\mathrm{ET}_{\mathrm{i}, \mathrm{s}}$ from the Noah LSM, and was shown to perform as well or better than the individual Fisher and Noah models when compared to eddy covariance flux tower data collected in areas representing major climate zones and land cover types in sub-Saharan Africa (Marshall et al., 2010). The major benefit of the hybrid model over the Noah LSM was the use of a Fisher-based $E T_{c}$ component driven by dynamic vegetation, which tended to better capture the seasonality of $\mathrm{ET}_{\mathrm{a}}$ at drier sites. The hybrid model performed best in humid areas, conditions representative of a significant portion of tropical Africa. The performance of the hybrid model at the humid sites was attributed to the use of Priestley-Taylor (equilibrium) $\mathrm{ET}_{\mathrm{p}}$ in the computation of $E T_{c}$, as implemented in the Fisher model. In the equilibrium case, advection is implicitly accounted for by $\alpha$. $\mathrm{ET}_{\mathrm{p}}$ is therefore driven primarily by $R_{N}$, so the Priestley-Taylor formulation performs better for energy-limited (dense) vegetation and more poorly for moisture-limited (sparse) vegetation (Mu et al., 2007), because surface resistance rapidly increases as soil dries out due to advection, decreasing $\alpha$ (Agam et al., 2010). Although constraints in the Fisher model account for changes in soil moisture, the relatively poor performance of the model in semiarid regions suggested that the model could be improved 
with the use of Penman $\mathrm{ET}_{\mathrm{p}}$, where advection is handled explicitly; however, further analysis revealed that both formulations gave similar results at all the sites. The model used in this chapter, therefore, retains the Priestley-Taylor approach, under the assumption that at large (satellite) scales, advection is driven primarily by the growth of the convective boundary layer, which in turn is driven by $R_{N}$ (Raupach, 2000).

\subsubsection{Data Handing and Processing}

The canopy component of the Fisher model was run at a daily time step and requires five inputs: NDVI, EVI, maximum air temperature, minimum relative humidity, and $R_{N}$. Daily maximum temperature and relative humidity were used instead of averages because the relationship between $\mathrm{ET}_{\mathrm{a}}$ and these variables is strongest during midday when convection is high. The climate data used to drive the $E T_{c}$ (Fisher) component of the hybrid model were derived from 3-hourly $0.25^{\circ}(\sim 25 \mathrm{~km})$ resolution GLDAS climate data (Rodell et al., 2004). The GLDAS data set is a synthesis of various reanalysis, remote sensing, and ground sources, including National Oceanic and Atmospheric Administration Global Data Assimilation System (NOAA/ GDAS) atmospheric fields, Climate Prediction Center (CPC) Merged Analysis of Precipitation fields (CMAP), and observation-driven shortwave and longwave radiation using the Air Force Weather Agency's AGRicultural METeorological modeling system. These data are available from 2001 to the present, while only the NOAA/ GDAS reanalysis is available for 2000. Saturation vapor pressure was computed using the Allen et al. (1998) temperature function and combined with specific humidity to estimate relative humidity. Global vegetation fields available at $0.05^{\circ}$ $(\sim 5 \mathrm{~km})$ spatial resolution from reflectance data acquired by the Moderate Resolution Imaging Spectroradiometer (MODIS) on board the Earth Observing System (EOS)Terra platform (Huete et al., 2002) were subset for sub-Saharan Africa. The vegetation index products consist of 16-day composites to reduce noise due to atmospheric effects. Postprocessing included a piecewise weighted least squares filter (Swets et al., 1999), which further reduces atmospheric effects that can degrade the signal. The $\mathrm{LE}_{\mathrm{i}, \mathrm{s}}$ (Noah) components of the hybrid model were downloaded and processed in a similar fashion to the GLDAS forcing data (Rodell et al., 2004). The model was run over the African domain considered in this study for 2000-2009.

\subsection{MODEL CALIBRATION AND VALIDATION}

\subsubsection{Study Area}

The Republic of Kenya, located approximately between $5^{\circ} 7^{\prime} \mathrm{N}$ and $4^{\circ} 39^{\prime} \mathrm{S}$ longitude, is part of the Greater Horn region of Africa along the Indian Ocean (SEDAC, 2005). Kenya has a surface area of $579,617 \mathrm{~km}^{2}$ comprising 8 provinces that are subdivided into 47 districts (Figure 8.1a). According to 2009 figures, the country's population was more than 30 million people, with nearly $22 \%$ of Kenyans living in urban centers (UN, 2009b). Farming is the primary livelihood of more than $75 \%$ of the population, conducted either on subsistence plots in marginal farming areas or on large plantations in the more arable areas (Uwechue, 1996), with less than 4\% 

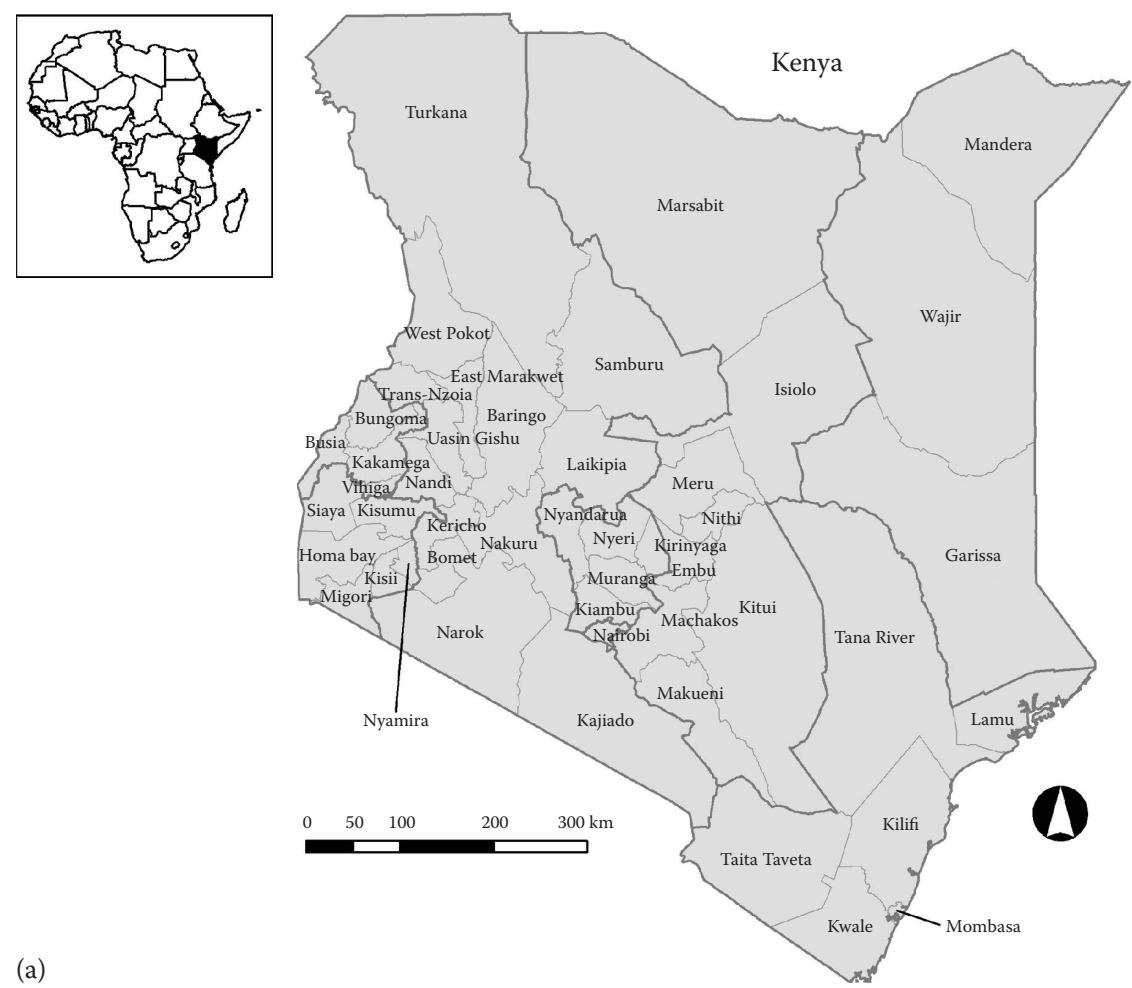

(a)

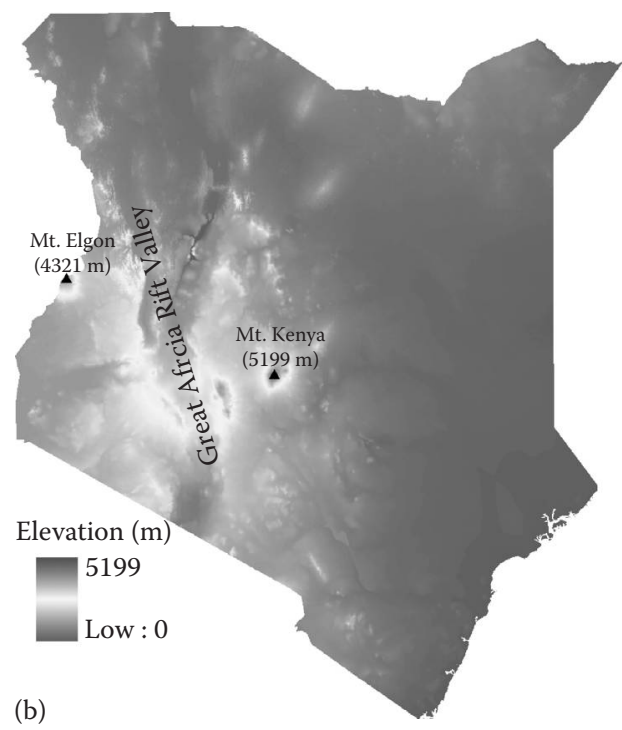

FIGURE 8.1 (See color insert.) Administrative boundaries of Kenya (a) and topographic map of Kenya (b). Forty-seven districts span eight provinces outlined in dark brown on the administrative map. The western and eastern highlands of Kenya are divided by the Great African Rift Valley shown on the topographic map. 
of people being pastoralists. Districts to the northwest and east are pastoral, transitioning to mixed agriculture and pastoral areas to the south, such as West Pokot, Baringo, and Laikipia districts (FEWS NET, 2010). The recent increase in drought frequency and intensity and conspiring factors such as poor trade infrastructure, poverty, lack of government intervention, HIV/AIDS, failed adoption of droughttolerant crops, and lack of grazing resources make these districts particularly food insecure. The most arable land is found in a high population density corridor consisting of Meru and Nithi districts to the east and Western Province to the west of the Great African Rift Valley (Figure 8.1b). These districts include major portions of the valley (Bomet, Nakuru, Kericho, Trans-Nzoia, and Uasin Gishu) and are characterized largely by cereal and dairy farming, while maize, the primary food staple, is the major crop grown outside these districts.

Kenya can be divided into five broad climatic zones: coastal, eastern/north, eastern/ south, eastern/central, and western rift valley (DSK, 2003). The rainfall pattern in Kenya is typically bimodal, with a short rainy season (October-December) driven by convergence and the southward migration of the Intertropical Convergence Zone and a long rainy season (March-May) driven by southeasterly trades and the Indian Monsoon in January-February. Figure 8.2a shows the average date of long rain onset in Kenya. The onset of rains for the vast majority of the country occurs in March, with the largest monthly totals occurring in May for the coastal areas and 1 month earlier in the central and northern areas of the country. More than $85 \%$ of crops (primarily staples) are planted during the month of onset. The western and eastern highlands ascend from the Great African Rift Valley. Orographic uplift enhances rainfall in the highlands, which receive the largest amount of rainfall $(>1000 \mathrm{~mm}$ per annum) in the country. The driest parts of the country $(<250 \mathrm{~mm}$ per annum) are in the lowlands of northern Kenya. Rainfall in the western rift valley is strongly influenced by Lake Victoria and orographic uplift in the western highlands. The development of deep convection and cumulous clouds brings rain throughout the year, with surges during the long rainy season and the lowest amounts in January-February. Given the extended long rainy season, crops are staggered, and the harvest season in the western rift valley (October-January) is much longer than the harvest season for the remainder of the country (July-August).

\subsubsection{Evapotranspiration and Crop Yield}

Water loss through transpiration is a consequence of carbon uptake, and, therefore, $\mathrm{ET}_{\mathrm{a}}$ often correlates well to fluctuations in plant biomass in areas of dense vegetation. Prolonged climate-related stress, as discussed earlier, results in lower carbon uptake and plant biomass over the growing season, thus reducing annual crop production and yield. Maize is the staple food throughout most of Kenya and is grown primarily during the long rainy season, so production and planted area statistics from this season of the year were deemed appropriate to evaluate the $\mathrm{ET}_{\mathrm{a}}$ hybrid model. The agricultural ministry conducts an exhaustive field campaign that measures cropped area (ha) before harvest and estimates crop production by counting bags of a particular crop at harvest (Freund, 2005). These point measurements are then extrapolated to each district, yielding a district-level estimate of crop area, production, and yield. For this study, crop production statistics at the district level from 2000 to 2004 were 


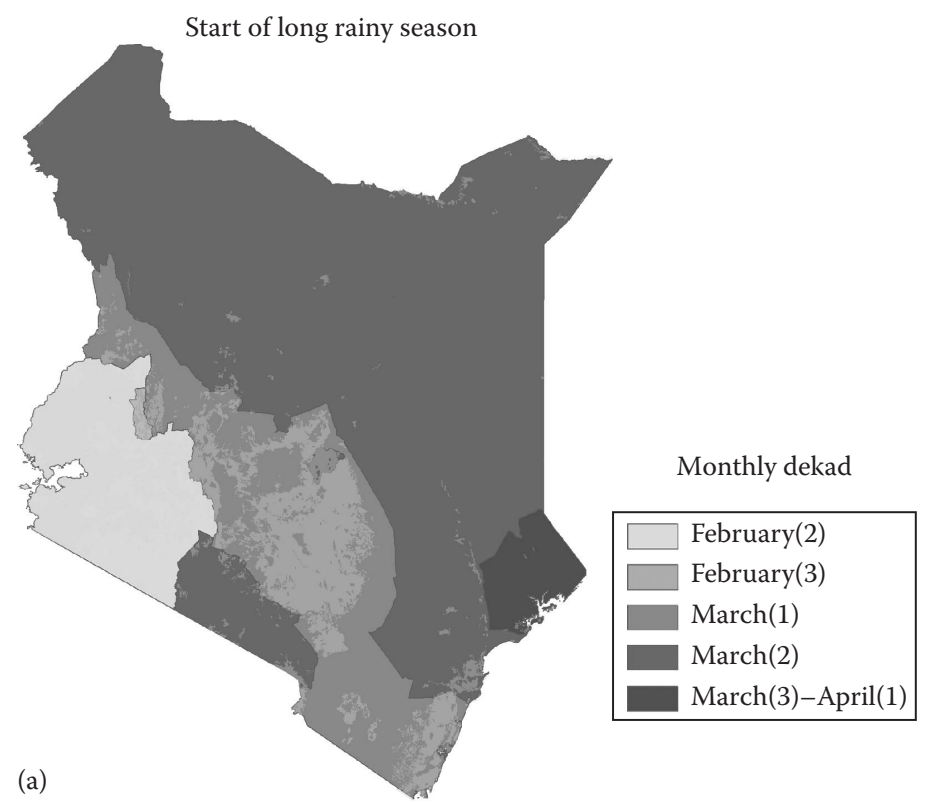

Evapotranspiration and yield

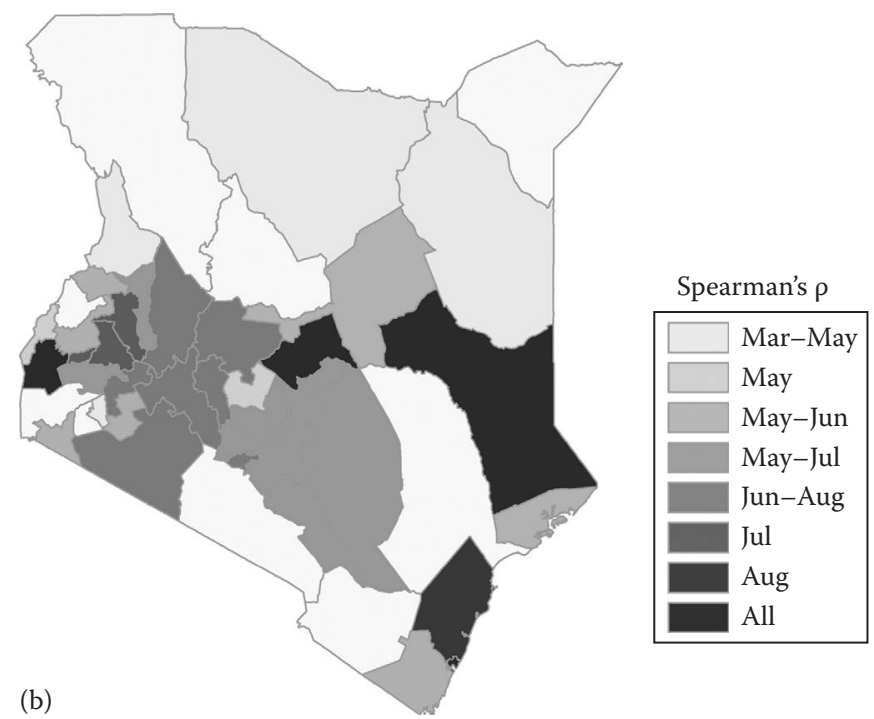

FIGURE 8.2 Mean date of long rain onset identified by the dekad (1-3) for each month, with yellow shading indicating cropped area (a) and months showing high $(\rho \geq 0.7)$ correlations between $\mathrm{ET}_{\mathrm{a}}$ and district-level maize yield (b). Districts in white showed no correlation between $\mathrm{ET}_{\mathrm{a}}$ and yield in any month, while districts in brown showed correlations outside the growing season. 
acquired from Kenya's Department of Resource Surveys and Remote Sensing of the Ministry of Planning and National Development. The hybrid (Fisher $E T_{c}+$ Noah $\mathrm{ET}_{\mathrm{i}, \mathrm{s}}$ ) model results were compared against the Noah $\mathrm{ET}_{\mathrm{a}}$ and $E T_{c}$ results from the Fisher model. $E T_{c}$ from the Fisher model was also included in the evaluation because it was expected that transpiration, a direct measure of moisture availability in the root zone, would track crop stress well on its own.

Statistics from 70 districts were aggregated to 47 districts to match a vector file that contained pre-2001 district-level administrative boundaries. The vector file was used to obtain monthly areal statistics from the $0.05^{\circ}$ hybrid (Fisher $E T_{c}+$ Noah $\mathrm{ET}_{\mathrm{i}, \mathrm{s}}$ ) and $0.25^{\circ}$ Noah gridded data sets. $\mathrm{ET}_{\mathrm{a}}$ totals $(\mathrm{mm})$ averaged over each of the 47 districts for each month in the extended long rainy season (March-August) were used in the comparison. Monthly anomalies were computed from the 5 year (2000-2004) means. The Spearman rank correlation coefficient $(\rho)$ was used to identify months where $\mathrm{ET}_{\mathrm{a}}$ anomalies correlated well with maize yield. This resulted in only five data points (i.e., one per year in study period) for each month of analysis. A $\rho \geq 0.7$ (confidence $=90 \%$ ) threshold was used to discern between strong and weak correlations. The Spearman rank correlation is a nonparametric technique used to detect monotonic trends (Sprent and Smeeton, 2007) and is essentially the Pearson correlation coefficient $(\mathrm{R})$ for ranked data where ties are accounted for by taking the arithmetic average of the ranks. The Spearman rank correlation was chosen for several reasons: (1) production data are highly uncertain and often contain several outliers that tend to limit the ability of parametric techniques; (2) crop metrics, such as seasonal average NDVI, tend to do well at discriminating between "wet" and "dry" years when crops are limited by rainfall, but poorly differentiate "good" and "very good" production years when relatively small differences in production are a result of nonclimatic factors (Funk and Verdin, 2009); and (3) it is appropriate for small sample sizes.

The map in Figure 8.2b demonstrates the regional seasonality in the relationship between $\mathrm{ET}_{\mathrm{a}}$ and yield, as indicated by the consensus of the two models on the correlation of yield to $\mathrm{ET}_{\mathrm{a}}$. For each district, the months in which monthly $\mathrm{ET}_{\mathrm{a}}$ anomalies correlate well $(\rho \geq 0.7)$ with yield from the hybrid model are identified in the figure. The months are nearly identical to those from the Noah model, but the correlations were typically lower for the latter. It is important to note that the correlations between $\mathrm{ET}_{\mathrm{a}}$ and maize yield reflect only climate-driven variability. It is therefore assumed that several nonclimatic factors, such as labor input and soil tilth, play a lesser role in controlling maize yield. Districts highlighted in white showed poor correlations across all the months, while districts in brown showed correlations outside the expected growing season. In 36 of the 47 districts (77\%), the $\mathrm{ET}_{\mathrm{a}}$ anomalies from the hybrid model were better correlated with yield than were Noah model ET anomalies, as assessed on a month-by-month basis. For four of the wettest districts (Bungoma, Kisii, Taita Taveta, and Vihigia), ET a anomalies from the Noah model were marginally better correlated with yield, at a low level of confidence $(<50 \%)$. Of the five remaining districts, four showed higher correlations between yield and Noah $\mathrm{ET}_{\mathrm{a}}$ than the hybrid model, but these correlations occurred during noncritical (outside the growing season) months of the year. The only district in which the Noah model provided significantly higher correlations during critical growing season 
months was in another wet district (Siaya), but the cause (or causes) of this result in this district is (are) unclear.

The variability in $\mathrm{ET}_{\mathrm{a}}$ and maize yield correlations and inconsistencies with the expected growing season are highest in Western Kenya. Possible causes for this include poor crop reporting or the importance of nonclimatic factors. The most probable cause, however, deals with the climate and planting regime of this region. The western districts of Kenya are characterized by fairly consistent rainfall and a staggered planting regime throughout the year, meaning the variability in $\mathrm{ET}_{\mathrm{a}}$ is low. Areas of low variability tend to transpire at or close to the atmospheric demand because they are not moisture limited. This could explain why some districts showed high correlations between $\mathrm{ET}_{\mathrm{a}}$ and maize yield for some of the districts and low to no correlations in other districts. For the majority of the crop-producing districts in Kenya, $\mathrm{ET}_{\mathrm{a}}$ appears to correlate with the grain-filling (reproductive) period of the seasonal calendar. The Rift Valley districts have a prolonged rainy season (February-September) and a relatively late harvest (October-February), so grain filling (June-August) is later than other districts. In the central and eastern highlands, the rainy season is shorter (March-June), and the harvest (July-September) is much earlier than the Rift Valley districts, so grain filling occurs earlier (May-July). Pastoral districts to the north have a shorter growing and later rainy season than the central and eastern highlands, so the highest correlation between $\mathrm{ET}_{\mathrm{a}}$ and maize yield is earlier, again reflecting the grain-filling period of the seasonal calendar. Districts along the southeast coast showed weak or no correlations between $\mathrm{ET}_{\mathrm{a}}$ and maize yield, and this is most likely due to the low variability in maize yield. These districts grow crops primarily during the short rainy season (October-January).

Districts highlighted with a graduated grayscale scheme in Figure 8.3 were selected for further analysis because they represent the most intensely cultivated and populated districts of the country. These districts showed significant $(\rho \geq 0.7)$ correlations between maize yield and modeled ET $_{\mathrm{a}}$ averaged over May-July, the critical grain-filling period of the seasonal calendar. The Spearman rank correlation between the hybrid and Noah model $\mathrm{ET}_{\mathrm{a}}$ and district-level yield in this focus area for the May-July season are shown in Figure 8.3a and b, respectively. Modeled $\mathrm{ET}_{\mathrm{a}}$ anomalies in these months tended to show the strongest correlations with maize yield and therefore may be the most optimal midseason predictors. In general, both models provided similar correlations, with slightly stronger predictive values from the hybrid model except in the Kitui District. Noah correlations were significantly lower in the East Marakwet and Nyeri districts, most likely because of poor observed rainfall representation and reanalysis data used to drive Noah $\mathrm{ET}_{\mathrm{a}}$. The apparent 2-3 month lag between optimal $\mathrm{ET}_{\mathrm{a}}$ (strongest $\mathrm{ET}_{\mathrm{a}}$-yield relationship) and rainfall onset is consistent with previous studies that showed a 2-3 month lagged relationship between rainfall onset and peak NDVI (Nicholson et al., 1990). This lag accounts for the vegetation response to accumulated soil moisture, which is most critical during the grain-filling period.

To further study the predictive capacity of midseason $\mathrm{ET}_{\mathrm{a}}$ for end-of-season yield, May-July $\mathrm{ET}_{\mathrm{a}}$ anomalies computed from monthly averages from each district polygon highlighted in Figure 8.3 were compared with yield anomalies in Figure 8.4. Here we examine anomalies in $\mathrm{ET}_{\mathrm{a}}$ from both models and $E T_{c}$ (canopy component only) 
Average May-July correlations with yield (hybrid)

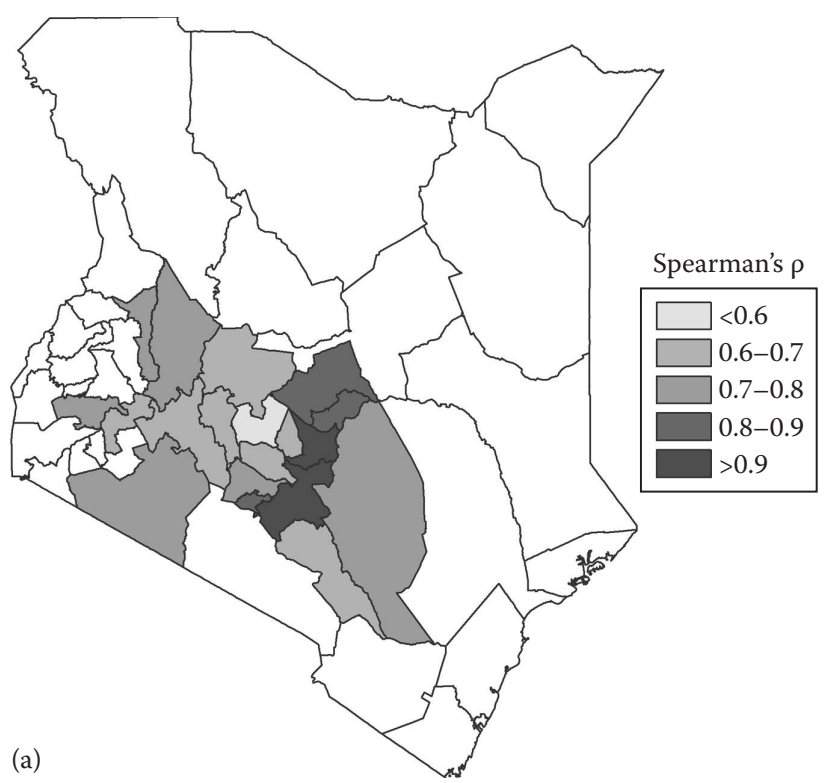

Average May-July correlations with yield (Noah)

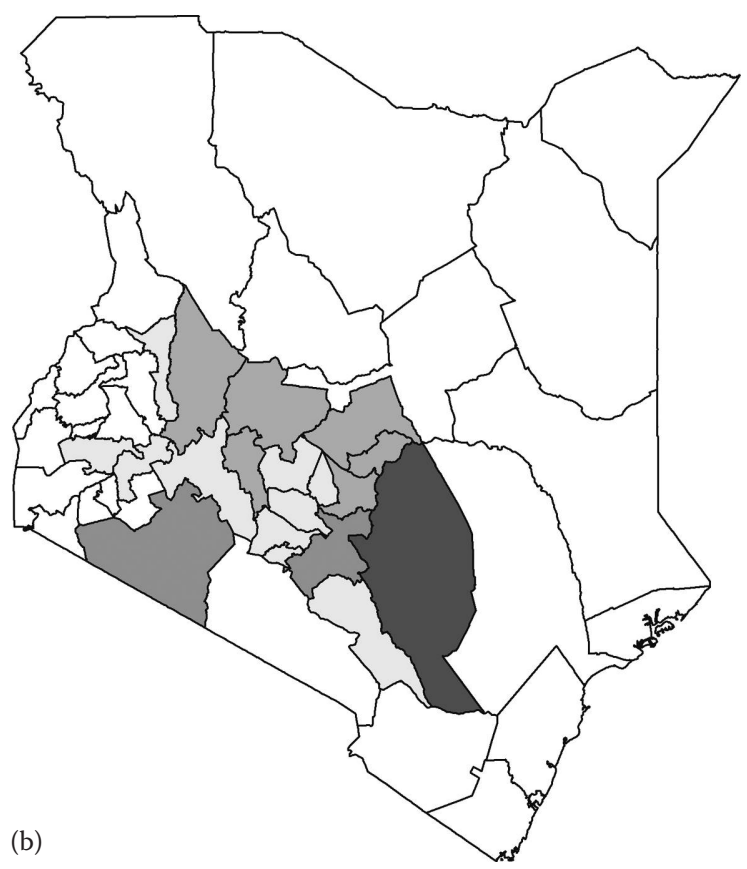

FIGURE 8.3 Spearman rank correlations for select districts between May-July average $\mathrm{ET}_{\mathrm{a}}$ and district-level crop yield (2000-2004) for the combined (Fisher $E T_{c}+\mathrm{Noah}_{\mathrm{ET}} \mathrm{i}, \mathrm{s}$ ) model (a) and Noah LSM (b). White indicates areas where correlations were 0. 


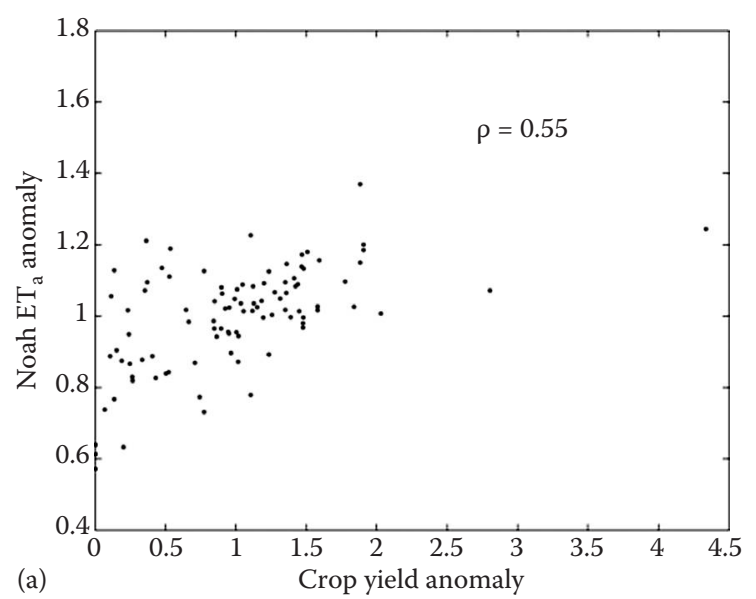

(a)
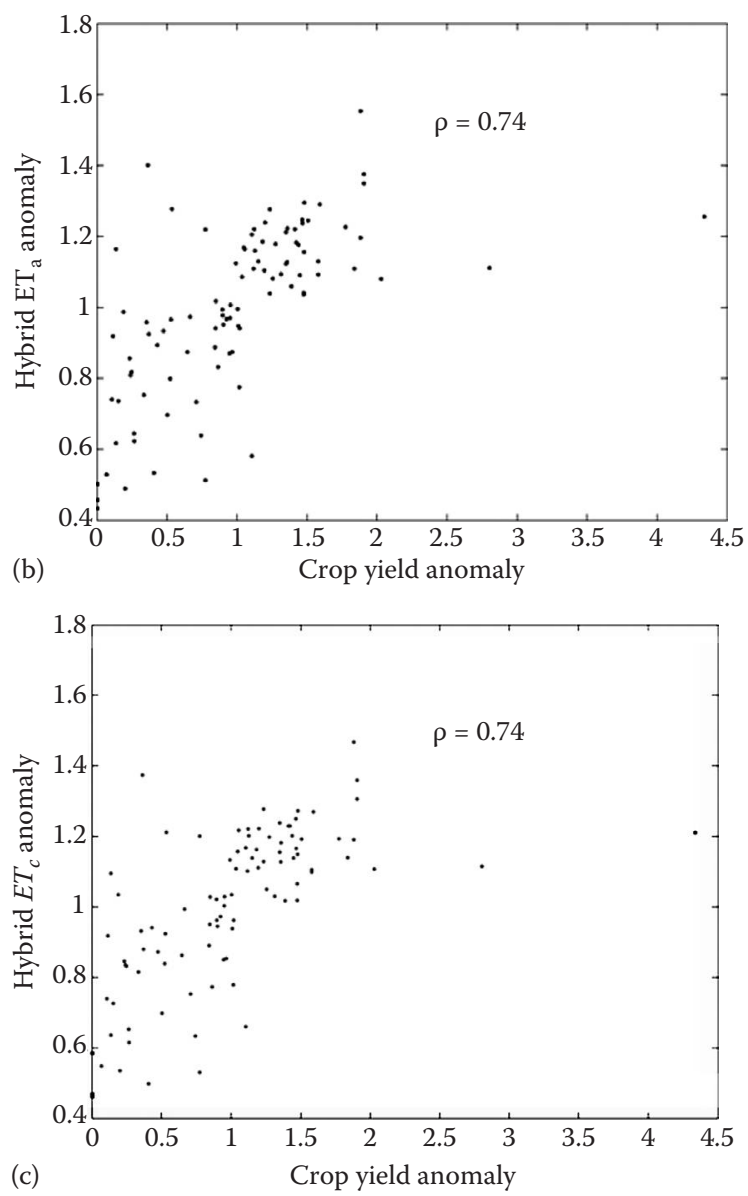

FIGURE 8.4 Comparison of crop yield anomalies with May-July $\mathrm{ET}_{\mathrm{a}}$ anomalies using $\mathrm{ET}_{\mathrm{a}}$ from Noah (a), $\mathrm{ET}_{\mathrm{a}}$ from the hybrid model (b), and $E T_{c}$ from the Fisher model $(N=95)(\mathrm{c})$. 
from the Fisher model, to determine the relative predictive power of $E T_{c}$ in isolation. The use of 19 districts and 5 years of yield data gave a total of 95 data points for analysis. The confidence levels were not computed, because each sample is not truly independent (i.e., wet and dry years will tend to cluster, because neighboring districts will exhibit similar climate and growth response). The correlation between Noah $\mathrm{ET}_{\mathrm{a}}$ anomalies and yield $(\rho=0.55, \mathrm{R}=0.57)$ was significantly lower than the hybrid model $(\rho=0.74, R=0.64)$ or the canopy component of the Fisher model $(\rho=0.74$, $\mathrm{R}=0.65$ ). However, the transpiration component correlations were similar to those from the hybrid model $\mathrm{ET}_{\mathrm{a}}$. From an operational standpoint, $E T_{c}$ is a preferred indicator because it requires fewer inputs to compute. $\mathrm{ET}_{\mathrm{a}}$ from the hybrid model and Fisher $E T_{c}$ each explained $\sim 55 \%$ of the variance in maize yield, which is within the acceptable range for crop monitoring applications related to food security.

\subsection{ET-BASED DROUGHT INDEX}

Given that $E T_{c}$ from the Fisher model appears to have utility in predicting end-ofseason yield variability, $E T_{c}$ was used in this section to develop a drought monitoring index analogous to the ESI introduced by Anderson et al. (2007), given by $1-\mathrm{ET}_{\mathrm{a}} /$ $\mathrm{ET}_{\mathrm{p}}$. As with WRSI, ET is constrained by the atmospheric water demand. An ESI value approaching 1 indicates very low $\mathrm{ET}_{\mathrm{a}}$, reflecting low soil moisture and associated crop stress conditions. As ESI approaches $0, \mathrm{ET}_{\mathrm{a}}$ approaches $\mathrm{ET}_{\mathrm{p}}$, which occurs when soil moisture is high and the crop is not constrained by a loss of water to the atmosphere. Here we formulate a modified version of the ESI focusing on crop stress and agricultural drought monitoring using the ratio of $E T_{c}$ to canopy $E T_{\mathrm{p}}$. Substituting the Fisher transpiration component into this relationship yields the following index:

$$
E S I_{c}=1-f_{g} f_{t} f_{m}\left(1-f_{\text {wet }}\right)
$$

The index eliminates the need for the estimation of $R_{N}$ used in $\mathrm{ET}_{\mathrm{p}}$. The $E S I_{c}$ requires only estimates of NDVI and EVI derived from remote sensing and air temperature and relative humidity derived from surface reanalysis meteorological data. This formulation neglects evaporation from the canopy and soil surface, which is reasonable given that crop stress is directly proportional to the amount of water available in the root zone. Marshall et al. (2010) demonstrated that the Fisher model for $E T_{c}$ is driven primarily by EVI, and, therefore, this index essentially tracks vegetation anomalies as modified by the air temperature and humidity response functions $\left(f_{t}\right.$ and $\left.f_{m}\right)$. Unlike VHI, which uses radiometric surface temperature as a proxy for soil dryness, this index uses surface reanalysis meteorological data (temperature, pressure, and specific humidity) to simulate soil dryness.

Seasonal (May-July) average $E S I_{c}$ was computed over Kenya from 2000 to 2009 at $0.05^{\circ}$ resolution using the data sources described in Section 8.3. To account for differences in $E S I_{c}$ across crop types and climatic zones and to improve comparability with other statistical drought indices, the $E S I_{c}$ data set was normalized by the mean and variance to form a Z-score. Z-scores standardize a sample distribution to a normal distribution. A Z -score of negative one represents $1 \sigma$ below the normal mean (0), while a Z-score of positive one represents $1 \sigma$ above the normal mean. Values ranged 


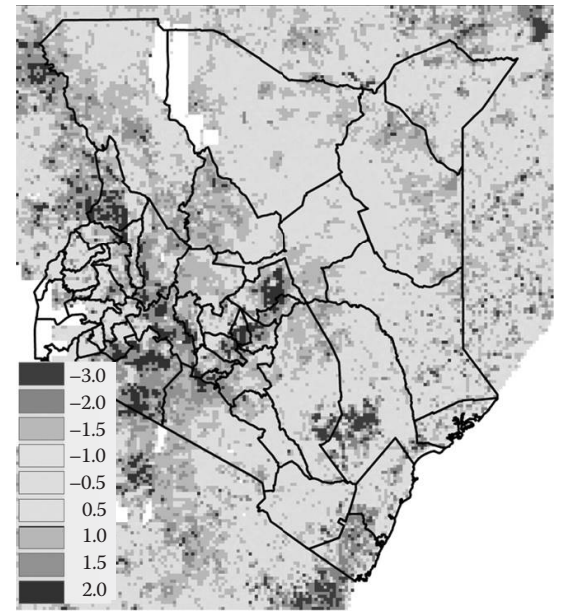

(a)

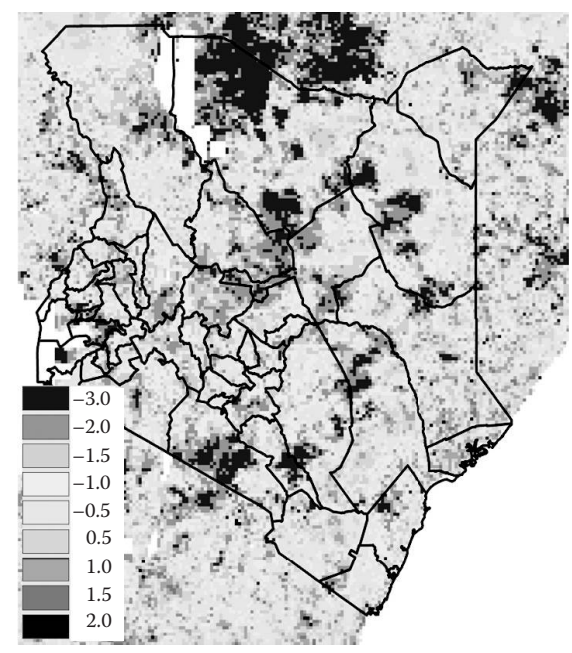

(c)

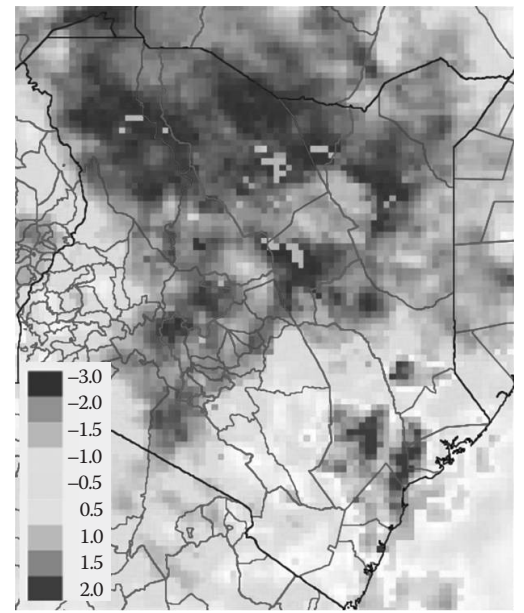

(b)

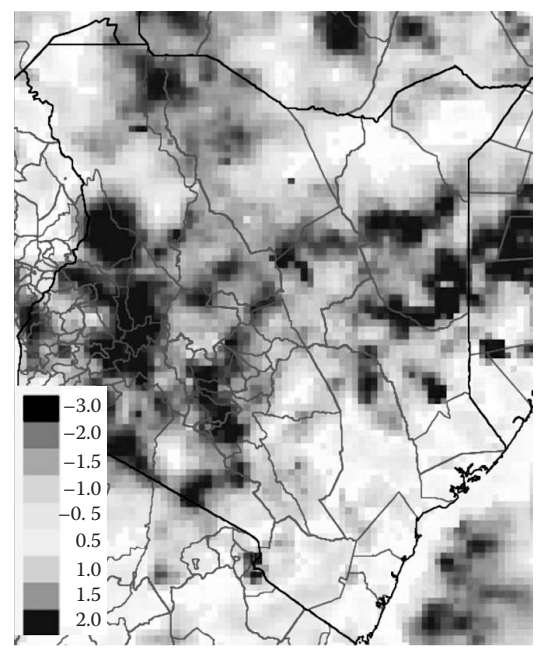

(d)

FIGURE 8.5 (See color insert.) May-July ESIc anomalies (a, b) and March-May SPI, (c, d) for Kenya in 2000 and 2003, respectively. Values are expressed as Z-scores of ESIc and the gamma probability of rainfall. Areas in white indicate missing data/bad values.

between $-2.5 \sigma$ and $+2.5 \sigma$, where negative values indicate wet anomalies and positive values indicate dry anomalies.

In Figure 8.5, $\mathrm{ESI}_{c}$ seasonal anomalies for Kenya are compared with SPI seasonal anomalies using visualizations created with the Early Warning Explorer (EWX: http://earlywarning.usgs.gov/fews/) interface recently developed by the Climate Hazards Group at the University of California, Santa Barbara, to inform food security researchers and policy makers. EWX is a web-based, desktop-like application for exploring geospatial as well as time series data related to famine 
early warning activities. The EWX enables food security researchers and policy makers to view related data sets side-by-side, and has many advanced features found in traditional GIS applications. The SPI was computed from $0.1^{\circ}(\sim 10 \mathrm{~km})$ resolution dekadal Rainfall Estimates (RFE) 2.0 data, and normalized to the period 2000-2009. RFE 2.0 rainfall combines a suite of data sources using the methodology described in Xie and Arkin (1997), using satellite data from the Meteosat geostationary satellites, the Advanced Microwave Sounding Unit (AMSU), the Special Sensor Microwave/Imager (SSM/I) infrared data, and meteorological data from approximately 1000 stations throughout sub-Saharan Africa that are part of the World Meteorological Organization's Global Telecommunication System. The SPI shown in Figure 8.5 was computed for the long rainy season (March-May) to accommodate for the time lag between precipitation and vegetation green-up. SPI ranges from $-3 \sigma$ to $+3 \sigma$, where positive and negative scores indicate dry and wet anomalies, respectively.

Figure 8.5 shows SPI and $E S I_{c}$ for an extremely dry year (2000) and wet year (2003). $E S I_{c}$ and SPI show general agreement in the major crop-producing districts. In 2000, strong positive (dry) $E S I_{c}$ anomalies and negative (dry) SPI anomalies can be seen in Nakuru, Narok, Nyandarua, Meru, Nithi, Embu, Muranga, Kiambu, and Nairobi. The negative (wet) $E S I_{c}$ anomalies observed in Nyeri cover an area that includes Mount Kenya (elevation $=5199 \mathrm{~m}$ ), where most of the precipitation is the result of orographic lifting. As a result, this area receives rainfall throughout most of the year and is not representative of other parts of the district. SPI is at a coarser spatial resolution than $E S I_{c}$ and is not well represented by meteorological stations in this area, which may contribute to the observed bias in SPI. Strong wet anomalies for both $E S I_{c}$ and SPI can be seen in southeastern districts along the coast. Normal conditions in the west of the country along Lake Victoria are well represented by both data sets as well. Food security reports corroborate these relatively localized patterns in $E S I_{c}$, which reflects the normal long rains confined to localized areas in the west, along the coast, and around Mount Kenya (Nyeri district) (FEWS NET, 2000). Food security reports in 2000 indicate high food insecurity in districts with chronic food shortages that include Turkana, Samburu, Marsabit, and Wajir with more sporadic insecurity in the districts of Isiolo, Garissa, and Mandera. The extremity of deficits in the north and east is less pronounced in ESI $I_{c}$ than SPI. This is most likely due to a low vegetation signal (i.e., low canopy cover) in these arid areas. In Marshall et al. (2010), the hybrid $\mathrm{ET}_{\mathrm{a}}$ model showed its weakest performance at the most arid eddy covariance flux tower sites, and this was attributed in part to the strong dependence of the model on EVI and the low EVI signal in these areas. The coarse resolution of the EVI data and dominance of bare soil in these areas could make EVI insensitive to phenological changes in drier areas. Other contributing factors could include poor specific humidity reanalysis data or soil moisture formulation. In 2003, wet anomalies can be seen for both indices in the major cropproducing districts. Neutral conditions and wet anomalies for both indices in the north and along the coast can be seen as well. The moderate dry anomaly in Uasin Gishu, West Pokot, and Trans-Nzoia districts that is not indicated by SPI may be a result of the delayed onset of rains in this area, which caused below-normal food production (FEWS NET, 2003). 
The $E_{S I}$ and SPI were also compared for 2009 (Figure 8.6) because this was a unique year climatically in the 10 year time series, with a delayed onset of the long rains throughout much of central, eastern, and coastal Kenya. This delay combined with 3 years of successive drought made 2009 particularly challenging for farmers. In the Kitui district (south-central Kenya), for example, maize prices increased by more

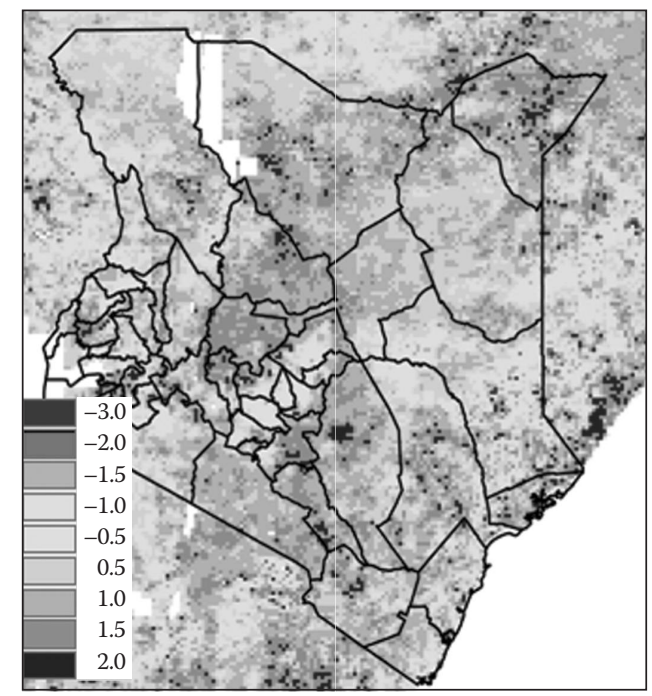

(a)

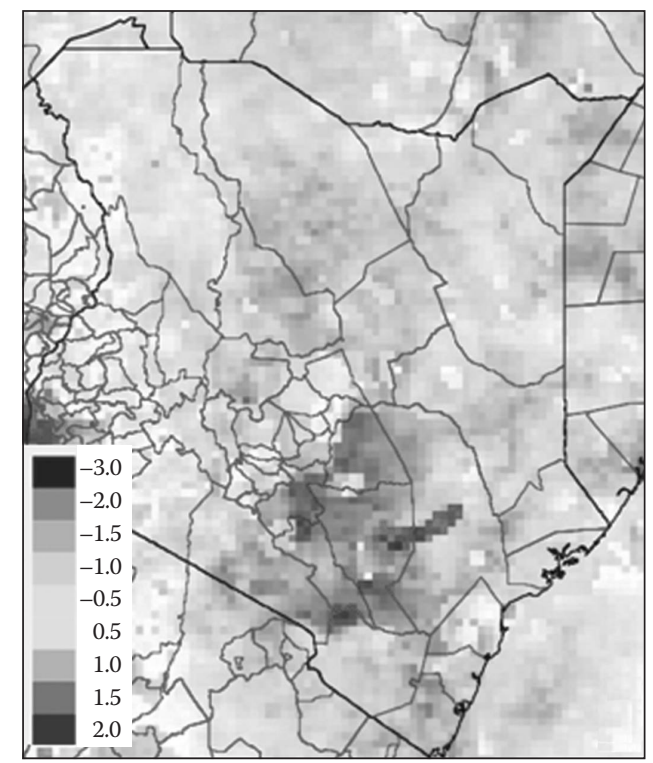

(b)

FIGURE 8.6 (See color insert.) Map of Kenya in 2009 showing May-July ESI ${ }_{c}$ anomalies (a), March-May SPI (b), and 


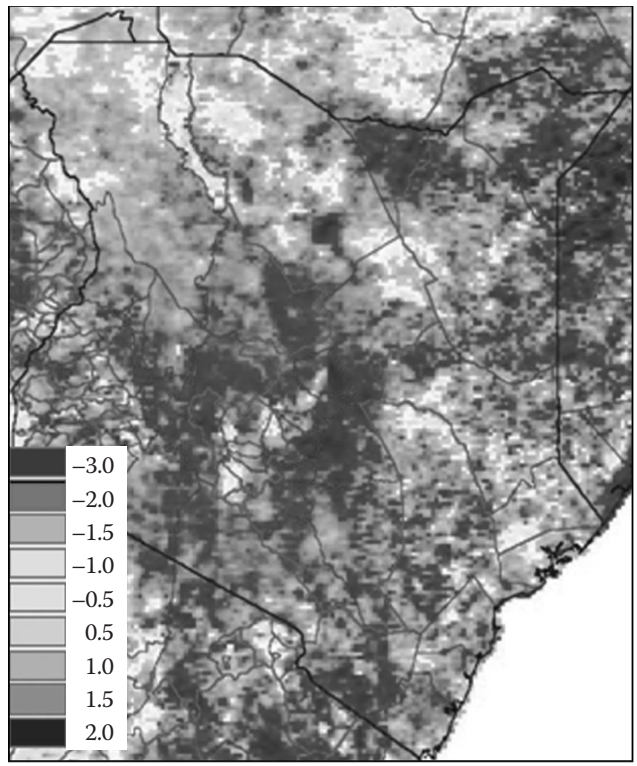

(c)

FIGURE 8.6 (continued) (See color insert.) May-July MODIS LST anomalies (c).

than $200 \%$ in response to crop failure (FEWS NET, 2009). Figure 8.6 compares $E S I_{c}$ and SPI along with anomalies in the MODIS land surface temperature (LST) product (Wan et al., 2004) computed for May-July. LST was included in the analysis, because it can be readily viewed with SPI on the EWX webpage, and because it provides proxy remote sensing information about the current surface moisture status. The LST product used on the EWX webpage is derived from the MODIS thermal sensor on board the Aqua platform, resampled to $0.05^{\circ}$ spatial resolution globally at a daily time step. $E S I_{c}$ provides a good representation of the range of food security conditions that existed in 2009. In that year, many districts in the west and center of the country with normal or slightly above-normal $E S I_{c}$ and SPI conditions (-0.5 to 0.0 ) were moderately food secure with localized areas of high food insecurity (FEWS NET, 2009). Marginal lands, such as those found in Baringo, Kitui, Machakos, and Makueni districts, were highly food insecure, as reflected by the large positive $E S I_{c}$ anomalies. Pronounced dry anomalies in the SPI appear in the Laikipia and Nyandarua districts, but, overall, the SPI fails to capture the severity of drought over the full region of insecurity, which may be partially explained by the LST anomaly map in Figure 8.6c. In 2009, temperatures were abnormally warm, which, when combined with late rains, would increase the evaporative moisture loss rate and enhance crop stress. These higher temperatures and vegetation stress are reflected over much of Kenya in the MODIS LST anomaly map, but they would not have been as clearly represented in the SPI, which is solely dependent on precipitation inputs and does not incorporate temperature into its calculation. As a result, both climatic drivers impacting the rate of water consumption and overall condition of crops in 2009 will be captured in $\mathrm{ET}_{\mathrm{a}}$-based indices, but not in precipitation-based indices like SPI. 


\subsection{DISCUSSION AND FUTURE WORK}

The $E S I_{c}$ index can be implemented in several ways to inform food security analysts and policy makers. One option would be to include it in an internet-based tool like EWX, which allows side-by-side user comparisons with other indices to give a more complete interpretation of agricultural droughts. EWX is stand-alone and interactive, allowing stakeholders at multiple levels to develop their own mitigation plans. The results of the analysis could be disseminated to the larger stakeholder community via weekly, seasonal, and annual reports. The African Dissemination Service is another online resource that includes a more comprehensive collection of data than EWX, but it is not interactive and requires additional software that may not be available to all stakeholders.

The poor representation of $E S I_{c}$ in the arid areas in the north and east of Kenya could be improved to better represent the dry and sparsely vegetated conditions there. $E S I_{c}$ is driven primarily by anomalies in vegetation indices and secondarily to surface temperature. Comparisons with other empirical indices that use vegetation and temperature as drivers, such as the VHI, will help to determine whether the more physical $E S I_{c}$ formulization and inclusion of a formal moisture constraint produces any significant improvements in moisture-limited areas. $E S I_{c}$ values in this study generally exhibited a skewed distribution over the period 2000-2009. Therefore, using Z-scores to represent anomalies may not properly stress the importance of extreme events, as was witnessed in the north and east of Kenya in 2000. The gamma distribution works particularly well for standardizing rainfall in Africa and should be evaluated, along with other distributions to improve interpretation of $E S I_{c}$. Given the stronger SPI signal in arid areas and $E S I_{c}$ signal in the primary agricultural areas, a combined index that uses standardized $E S I_{c}$ and SPI could potentially be a powerful tool for crop stress monitoring. Given the lagged relationship between rainfall and vegetation response, a simple autoregressive model of rainfall and vegetation could be used to reformulate the $E S I_{c}$ index in terms of precipitation and temperature. The index could then be back-casted to measure historical trends in crop stress and projected to determine crop stress probabilities under future Intergovernmental Panel on Climate Change (IPCC) climate scenarios.

The $\mathrm{ET}_{\mathrm{a}}$ model hybrid could also be used to improve yield estimate crop models, defining start and end of season at a higher resolution than data sets currently used in sub-Saharan Africa. This would improve the crop phase adjusted $\mathrm{ET}_{\mathrm{p}}$ used in crop models, such as WRSI. ET $\mathrm{a}$ is a leading component of the surface energy and water balance. Improved estimates of $\mathrm{ET}_{\mathrm{a}}$ would be of benefit in applying crop models for monitoring crop stress.

\subsection{CONCLUSIONS}

Precipitation, soil moisture, and vegetation-based indices have historically been used to monitor crop stress. ET is more intimately connected to moisture available to crops under stress than is precipitation or volumetric soil moisture, but it has not been used extensively in the past because of poor parameterization and a general lack of calibration and validation data. In this chapter, we presented a simple lowcost model for estimating $\mathrm{ET}_{\mathrm{a}}$ that combines remote sensing and surface reanalysis 
meteorological data. The model was evaluated against an energy and water balance approach to estimating $\mathrm{ET}_{\mathrm{a}}$ using maize yield data in Kenya. The analysis revealed that the canopy component of the $\mathrm{ET}_{\mathrm{a}}$ model performed as well as the hybrid model in areas of dense vegetation cover, given its sensitivity to root zone moisture.

The canopy component of the $\mathrm{ET}_{\mathrm{a}}$ was used to parameterize a new vegetationtemperature-based crop stress index. Unlike other vegetation-temperature indices, the new index includes a moisture constraint on crop health and incorporates a more realistic parameterization of vegetation with the inclusion of EVI and temperature by including an optimal temperature-response function. However, like other vegetationbased drought indices, the coarse resolution of satellite imagery used to drive the model fails to adequately capture the vegetation signal (and crop stress) in arid regions. For the major crop-producing areas of Kenya, however, the analysis demonstrated that the $E T_{c}$-based index is an effective crop monitoring tool using yield data and food security reports. The index, which is partially derived from remote sensing, is seen as an improvement on remotely sensed vegetation and temperature indices, because the formulization includes more general concepts on light and soil moisture limitation and surface reanalysis improves the temporal resolution of model inputs. Precipitationbased indices, which are currently used in sub-Saharan Africa, are a good indicator of moisture supply, but do not account for atmospheric moisture demand $\left(\mathrm{ET}_{\mathrm{p}}\right)$, which can be critical to maintaining plant health, especially during the reproductive phase. Atmospheric demand is directly proportional to surface temperature. Combining an index of moisture supply with a temperature component that captures the demand side would help to characterize not only onset conditions but the reproductive phase of crop growth as well. A compound index that includes $E T_{c}$ and precipitation would therefore give a more complete picture of crop development.

The use of ET $_{\mathrm{a}}$-driven models in agricultural studies is still in its infancy in subSaharan Africa. Dense eddy covariance flux tower and lysimeter data sets collected in selected areas of sub-Saharan Africa combined with upscaling techniques provide a test bed to further refine the $\mathrm{ET}_{\mathrm{a}}$ model and crop stress index and apply them to an array of questions related to agricultural development.

\section{ACKNOWLEDGMENTS}

This research was supported by the U.S. Agency for International Development Famine Early Warning System Network, under U.S. Geological Survey Cooperative Agreement \#G09AC00001, and the National Aeronautics and Space Administration, under Precipitation Science Grant \#NNX07AG266. Special thanks to Gideon Galu, who provided the agricultural statistics from the government of Kenya.

\section{REFERENCES}

Agam, N., W.P. Kustas, M.C. Anderson, J.M. Norman, P.D. Colaizzi, T.A. Howell, J.H. Prueger, T.P. Meyers, and T.B. Wilson. 2010. Application of the Priestley-Taylor approach in a two-source surface energy balance model. Journal of Hydrometeorology 95:185-198.

Allen, R.G. 2000. Using the FAO-56 dual crop coefficient method over an irrigated region as part of an evapotranspiration intercomparison study. Journal of Hydrology 229:27-41. 
Allen, R.G., L.S. Pereira, D. Raes, and M. Smith. 1998. Crop EvapotranspirationGuidelines for Computing Crop Water Requirements. Rome, Italy: Food and Agriculture Organization of the United Nations.

Alley, W.M. 1984. The Palmer drought severity index: Limitations and assumptions. Journal of Climate and Applied Meteorology 23:1100-1109.

Anderson, M.C., J.M. Norman, J.R. Mecikalski, J.A. Otkin, and W.P. Kustas. 2007. A climatological study of evapotranspiration and moisture stress across the continental United States based on thermal remote sensing: 1. Model formulation. Journal of Geophysical Research 112:D10117.

Anyamba, A. and J.R. Eastman. 1996. Interannual variability of NDVI over Africa and its relation to El Niño/Southern Oscillation. International Journal of Remote Sensing 17:2533-2548.

Betts, A.K., F. Chen, E. Mitchell, and Z.I. Janjic. 1997. Assessment of the land surface and boundary layer models in two operational versions of the NCEP Eta Model using FIFE data. Monthly Weather Review 125:2896-2916.

Chen, F., K.W. Manning, M.A. LeMone, S.B. Trier, J.G. Alfieri, R. Roberts, M. Tewari, D. Niyogi, T.W. Horst, S.P. Oncley, J.B. Basara, and P.D. Blanken. 2007. Description and evaluation of the characteristics of the NCAR high-resolution land data assimilation system. Journal of Applied Meteorology and Climatology 46:694-713.

Chen, F., K. Mitchell, J. Schaake, Y. Xue, H. Pan, V. Koren, Q.Y. Duan, M. Ek, and A. Betts. 1996. Modeling of land surface evaporation by four schemes and comparison with FIFE observations. Journal of Geophysical Research 101:2896-2916.

Doorenbos, J. and W.O. Pruitt. 1977. Crop water requirements. FAO irrigation and drainage paper 24, Rome, Italy: United Nation Food and Agriculture Organization.

Dracup, J.A., K.S. Lee, and E.G. Paulson, Jr. 1980. On the definition of droughts. Water Resources Research 16:297-302.

DSK. 2003. National Atlas of Kenya. Nairobi, Kenya: Survey of Kenya.

FEWS NET. 2000. Kenya Food Security Update: July 2000. Washington, DC: United States Agency for International Development.

FEWS NET. 2003. Kenya Food Security Update-September 5, 2003. Washington, DC: United States Agency for International Development.

FEWS NET. 2009. Kenya Food Security Outlook July to December 2009. Washington, DC: United States Agency for International Development.

FEWS NET. 2010. Kenya: Food Security Framework. Washington, DC: United States Agency for International Development.

FFP. 2010. Fact Sheet: Office of Food for Peace 2009 Statistics. Washington, DC: United States Agency for International Development.

Fisher, J.B., K.P. Tu, and D.D. Baldocchi. 2008. Global estimates of the land-atmosphere water flux based on monthly AVHRR and ISLSCP-II data, validated at 16 FLUXNET sites. Remote Sensing of Environment 112:901-919.

Freund, J.T. 2005. Estimating crop production in Kenya: A multi-temporal remote sensing approach. Master's thesis, Santa Barbara, CA: University of California-Santa Barbara.

Funk, C. and J. Verdin. 2009. Real-time decision support systems: The famine early warning system network. In Satellite Rainfall Applications for Surface Hydrology, eds. M. Gebremichael and F. Hossain, p. 327. New York: Springer.

Guttman, N.B. 1999. Accepting the standardized precipitation index: A calculation algorithm. Journal of the American Water Resources Association 35:311-322.

Heim, R.R. 2002. A review of twentieth-century drought indices used in the United States. Bulletin of the American Meteorological Society 83:1149-1165.

Hogue, T.S., L. Bastidas, H. Gupta, S. Sorooshian, K. Mitchell, and W. Emmerich. 2005. Evaluation and transferability of the Noah land surface model in semiarid environments. Journal of Hydrometeorology 6:68-84. 
Huete, A., K. Didan, T. Miuru, E.P. Rodriguez, X. Gao, and L.G. Ferreira. 2002. Overview of the radiometric and biophysical performance of the MODIS vegetation indices. Remote Sensing of Environment 83:195-213.

Jarvis, P. and K. McNaughton. 1986. Stomatal control of transpiration: Scaling up from leaf to region. Advances in Ecological Research 15:1-50.

Jones, H.G. 1992. Plants and Microclimate: A Quantitative Approach to Environmental Plant Physiology. Cambridge, MA: Cambridge University Press.

June, T., J.R. Evans, and G.D. Farquhar. 2004. A simple new equation for the reversible temperature dependence of photosynthetic electron transport: A study on soybean leaf. Functional Plant Biology 31:275-283.

Kalnay, E., M. Kanamitsu, R. Kistler, W. Collins, D. Deaven, L. Gandin, M. Iredell, S. Saha, G. White, J. Wollen, Y. Zhu, A. Keetmaa, R. Reynolds, M. Chelliah, W. Ebisuzaki, W. Higgins, J. Janowiak, K.C. Mo, C. Ropelewski, J. Wang, R. Jenne, and D. Joseph. 1996. The NCEP/NCAR 40-year reanalysis project. Bulletin of the American Meteorological Society 77:437-471.

Karl, T.R. 1986. The sensitivity of the Palmer drought severity index and Palmer's Z-Index to their calibration coefficients including potential evapotranspiration. Journal of Climate and Applied Meteorology 25:77-86.

Karnieli, A., M. Bayasgalan, Y. Bayarjargal, N. Agam, S. Khudulmur, and C.J. Tucker. 2006. Comments on the use of the vegetation health index over Mongolia. International Journal of Remote Sensing 27:2017-2024.

Keyantash, J. and J.A. Dracup. 2002. The quantification of drought: An evaluation of drought indices. Bulletin of the American Meteorological Society 83:1167-1180.

Kogan, F.N. 1995. Application of vegetation index and brightness temperature for drought detection. Advances in Space Research 15:91-100.

Mahfouf, J.F. and J. Noilhan. 1991. Comparative study of various formulations of evaporations from bare soil using in situ data. Journal of Applied Meteorology 30:1354-1365.

Marshall, M., K. Tu, C. Funk, J. Michaelsen, P. Williams, C. Williams, J. Ardö, B. Marie, B. Cappelaere, A. de Grandcourt, A. Nickless, Y. Nouvellon, R. Scholes, and W. Kutsch. 2011. Combining surface reanalysis and remote sensing data for monitoring evapotranspiration (in press).

McGuire, J.K. and W.C. Palmer. 1957. The 1957 drought in the eastern United States. Monthly Weather Review 85:305-314.

McKee, T.B., N.J. Doesken, and J. Kleist. 1993. The relationship of drought frequency and duration to time scales. Eighth Conference on Applied Climatology, American Meteorological Society, Anaheim, CA, January 17-22.

Monteith, J.L. 1965. Evaporation and environment. Symposia of the Society for Experimental Biology 19:205-234.

Mu, Q., M. Zhao, F.A. Heinsch, M. Liu, H. Tian, and S.W. Running. 2007. Evaluating water stress controls on primary production in biogeochemical and remote sensing based models. Journal of Geophysical Research 12:01010.01029/02006JG000179.

Narasimhan, B. and R. Srinivasan. 2005. Development and evaluation of soil moisture deficit index (SMDI) and evapotranspiration deficit index (ETDI) for agricultural drought monitoring. Agricultural and Forest Meteorology 133:69-88.

Nicholson, S.E., M.L. Davenport, and A.R. Malo. 1990. A comparison of the vegetation response to rainfall in the Sahel and East Africa, using normalized difference vegetation index from NOAA AVHRR. Climatic Change 17:209-241.

Palmer, W.C. 1965. Meteorological Drought. Research Paper No. 45, Washington, DC: U.S. Department of Commerce Weather Bureau.

Penman, H.L. 1948. Natural evaporation from open water, bare soil and grass. Proceedings of the Royal Society of London. Series A, Mathematical and Physical Sciences 193:120-145. 
Philippon, N., L. Jarlan, N. Martiny, P. Camberlin, and E. Mougin. 2007. Characterization of the interannual and intraseasonal variability of West African vegetation between 1982 and 2002 by means of NOAA AVHRR NDVI data. Journal of Climate 20:1202-1218.

Potter, C.S., J.T. Randerson, C.B. Field, P.A. Matson, P.M. Vitousek, H.A. Mooney, and S.A. Klooster. 1993. Terrestrial ecosystem production: A process model based on global satellite and surface data. Global Biogeochemical Cycles 7:811-841.

Priestley, C.H.B. and R.J. Taylor. 1972. On the assessment of surface heat flux and evaporation using large-scale parameters. Monthly Weather Review 100:81-92.

Raupach, M.R. 2000. Equilibrium evaporation and the convective boundary layer. BoundaryLayer Meteorology 96:107-142.

Rodell, M., P.R. Houser, U. Jambor, J. Gottschalck, K. Mitchell, C.-J. Meng, K. Arsenault, B. Cosgrove, J. Radakovich, M. Bosilovich, J.K. Entin, J.P. Walker, D. Lohmann, and D. Toll. 2004. The global land data assimilation system. Bulletin of the American Meteorological Society 85:381-394.

Rouse, J.W. Jr., R.H. Haas, D.W. Deering, and J.A. Schell. 1974. Monitoring the vernal advancement of retrogradation of natural vegetation. Greenbelt, MD: ASA/GSFC.

SEDAC. 2005. Gridded Population of the World, version 3 (GPWv3). Center for International Earth Science Information Network, Columbia University and Centro Internacional de Agricultura Tropical. http://sedac.ciesin.columbia.edu/gpw/ (accessed July 8, 2011).

Sellers, P.J. 1987. Canopy reflectance, photosynthesis, and transpiration, II. The role of biophysics in the linearity of their interdependence. Remote Sensing of Environment 21:143-183.

Senay, G.B. and J. Verdin. 2003. Characterization of yield reduction in Ethiopia using a GISbased crop water balance model. Canadian Journal of Remote Sensing 29:687-692.

Shanahan, J.F. and D.C. Nielsen. 1987. Influence of growth retardants (anti-gibberellins) on corn vegetative growth, water use, and grain yield under different levels of water stress. Agronomy Journal 79:103-109.

Sprent, P. and N.C. Smeeton. 2007. Applied Nonparametric Statistical Methods. New York: Chapman and Hall/CRC.

Stegman, E.C. 1982. Corn grain yield as influenced by timing of evapotranspiration deficits. Irrigation Science 3:75-87.

Swets, D.L., B.C. Reed, J.R. Rowland, and S.E. Marko. 1999. A weighted least-squares approach to temporal smoothing of NDVI. Proceedings of the 1999 ASPRS Annual Conference, Portland, OR, May 17-21.

UN. 2009a. The Millennium Development Goals Report. New York: United Nations.

UN. 2009b. World urbanization prospects: The 2009 revision population database. Population Division of the Department of Economic and Social Affairs of the United Nations Secretariat, http://esa.un.org/wup2009/unup/index.asp?panel=1 (accessed on November 15, 2009).

Uwechue, R. (ed.). 1996. Africa Today. London, U.K.: Africa Books Limited.

Wan, Z., Y. Zhang, Q. Zhang, and Z.-L. Li. 2004. Quality assessment and validation of the MODIS global land surface temperature. International Journal of Remote Sensing 25:261-274.

Xie, P. and P.A. Arkin. 1997. Global precipitation: A 17-year monthly analysis based on gauge observations, satellite estimates, and numerical model outputs. Bulletin of the American Meteorological Society 78:2539-2558. 

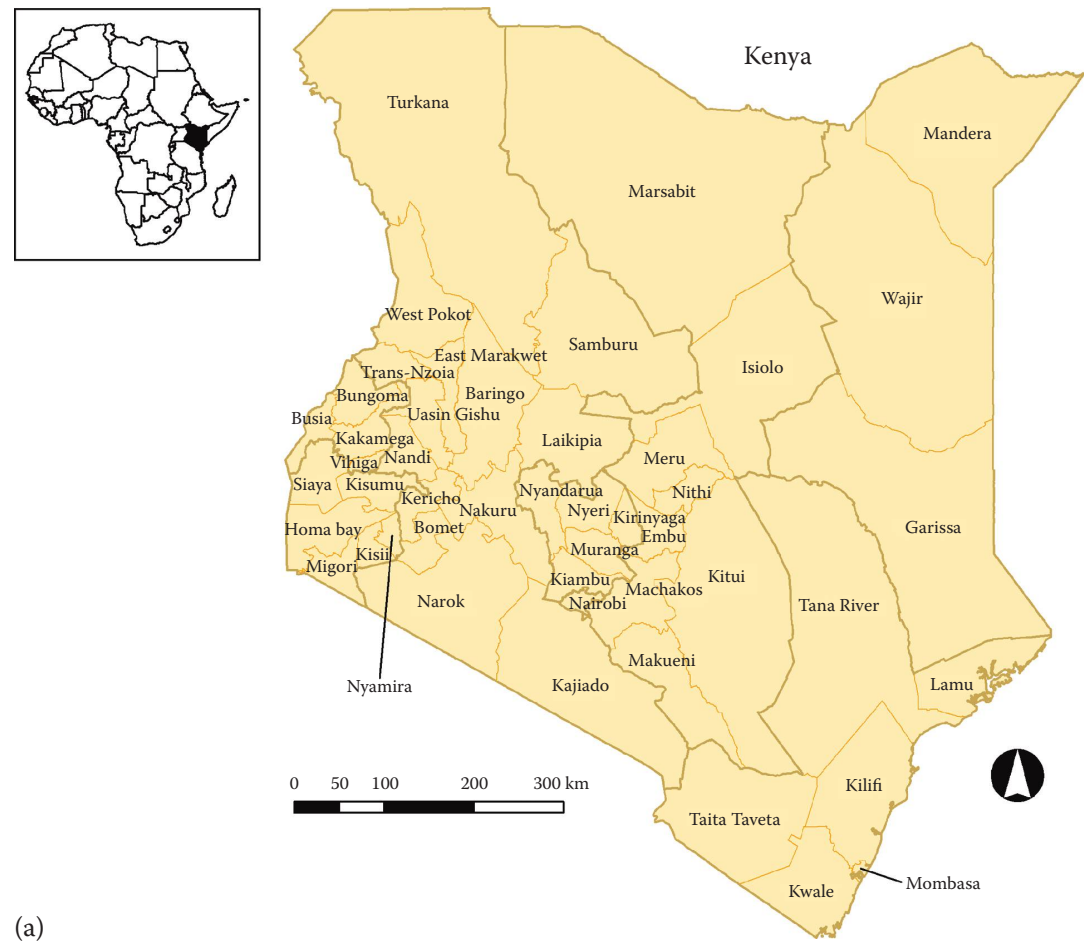

(a)

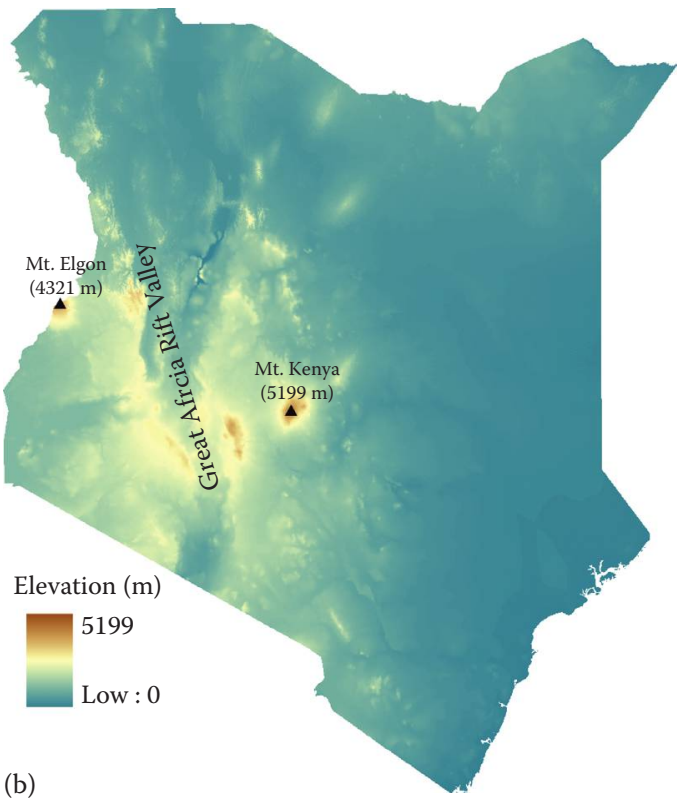

FIGURE 8.1 Administrative boundaries of Kenya (a) and topographic map of Kenya (b). Forty-seven districts span eight provinces outlined in dark brown on the administrative map. The western and eastern highlands of Kenya are divided by the Great African Rift Valley shown on the topographic map. 


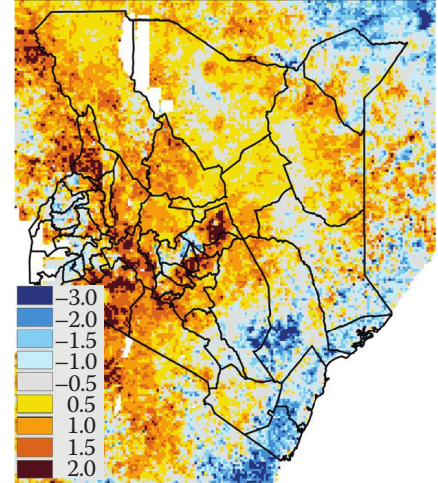

(a)

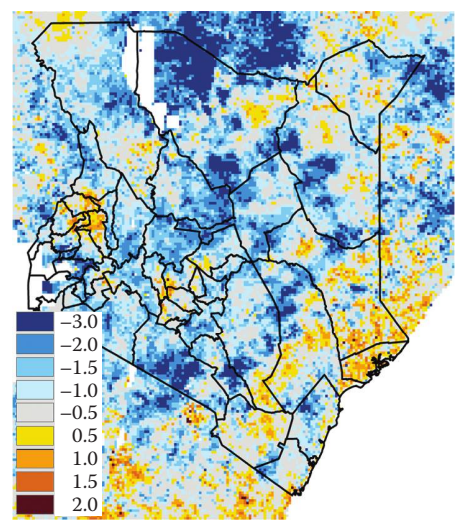

(c)

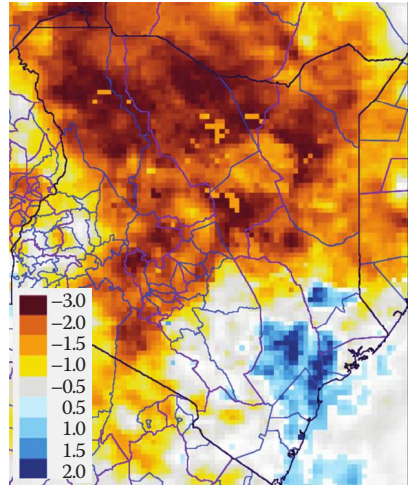

(b)

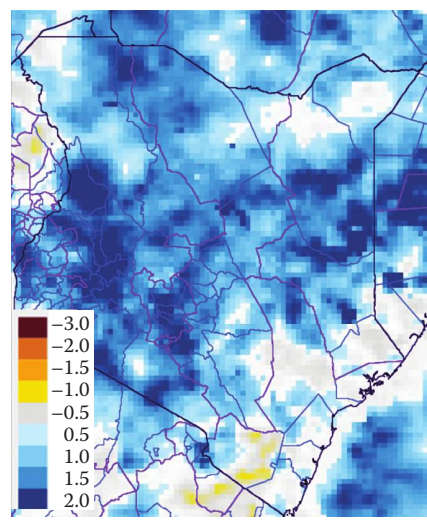

(d)

FIGURE 8.5 May-July ESIc anomalies (a, b) and March-May SPI, (c, d) for Kenya in 2000 and 2003, respectively. Values are expressed as Z-scores of ESIc and the gamma probability of rainfall. Areas in white indicate missing data/bad values. 


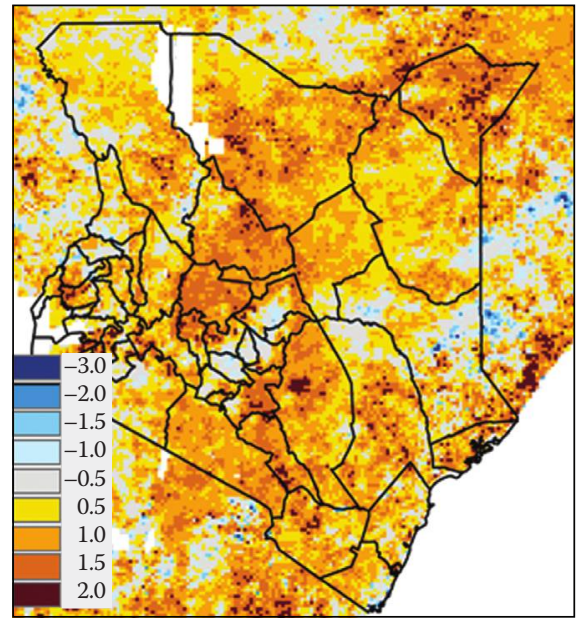

(a)

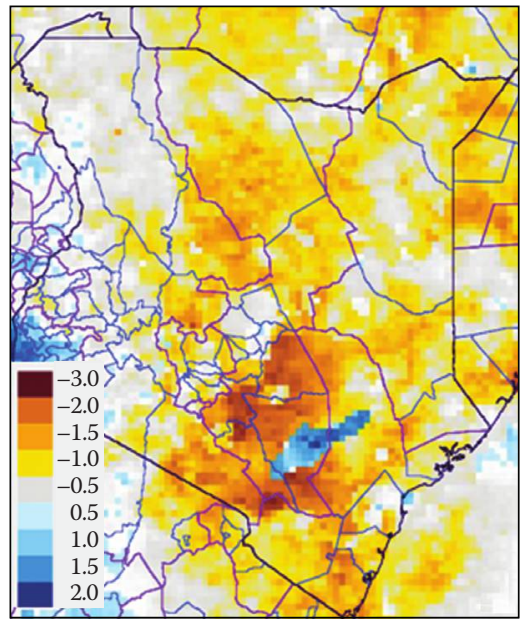

(b)

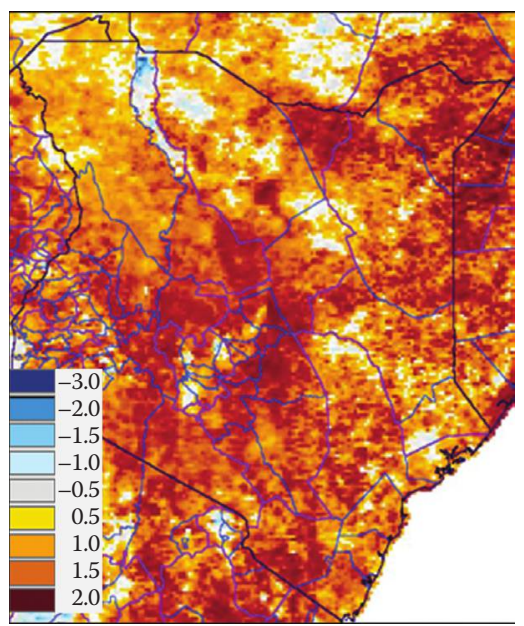

(c)

FIGURE 8.6 Map of Kenya in 2009 showing May-July ESI anomalies (a), March-May SPI (b), and May-July MODIS LST anomalies (c). 